\title{
Title: An endogenous Rtn4/Nogo-interacting micropeptide that modulates synaptic plasticity with age.
}

\section{Affiliations:}

${ }^{1}$ Department of Cell and Molecular Biology, Tulane University; New Orleans, LA, USA.

${ }^{2}$ Tulane University Transgenic Core Facility; New Orleans, LA, USA.

${ }^{3}$ Department of Biochemistry and Molecular Biology; LSU School of Medicine and Health Sciences Center, New Orleans, LA, USA

${ }^{4}$ The Proteomics Core Facility, LSUHSC; New Orleans, LA, USA

*Corresponding author. Email: learls@tulane.edu 
Abstract: 100-250 amino acid “micropeptides” are hidden throughout mammalian genomes, though few functional studies of micropeptides are published. Here, we describe a micropeptide known as the Plasticity -Associated Neural Transcript Short (Pants), located in the 22q11.2 region of the human genome, the microdeletion of which conveys a high risk for schizophrenia. Our data show that Pants is upregulated in early adulthood in the mossy fiber circuit of the hippocampus, where it exerts a powerful negative effect on long-term potentiation (LTP). Pants is secreted from neurons, where it associates with synapses but is rapidly degraded with stimulation. Pants dynamically interacts with Rtn4/Nogo, a well-studied regulator of adult plasticity. This study shows that neural micropeptides can act as architectural modules that increase the diversity of the known proteome. 
Schizophrenia (SZ) is a multifactorial disease that typically arises in late adolescence to early adulthood. The identification of molecular pathways that differentially influence brain function with adult maturation is key to understanding the age dependence of schizophrenia vulnerability.

A microdeletion at chromosome 22q11.2 in humans, which causes the 22q11.2 deletion syndrome (22q11.2DS) conveys one of highest known genetic risks for schizophrenia, with 25\% of 22q11.2DS patients developing SZ (1). Mouse models of the 22q11.2DS, carrying a deletion of the syntenic region on mouse chromosome 16, show robust, age-dependent phenotypes in multiple brain regions associated with SZ (2-6). For example, at and beyond 16 weeks of age, 22q11.2DS mouse models display increased long term potentiation (LTP) at hippocampal CA3-CA1 synapses that is associated with decreased performance in cognitive tasks (5). This serves as a sensitive cellular model for age-dependent onset of cognitive endophenotypes of SZ. While it is clear that multiple genes in the 22q11.2 region contribute to age-dependent hippocampal defects, not all of the genes involved have been identified. Small open reading frames (sORFs) are newly-recognized genomic elements that encode for small peptides (SEPs/micropeptides) of $\sim 100-250$ amino acids or less. sORFs are found throughout the genome (7), including in elements previously designated as non-coding RNAs (810), in antisense transcripts and in the assumed untranslated regions of larger mRNAs (11-14). Because of their simplicity, micropeptides make attractive candidates for elements that can be translated or degraded on the rapid timescale of brain activity. Further, because micropeptides lack complex structures that can affect multiple pathways, they may make for highly specific therapeutic targets. Molecular functions have been attributed to a few micropeptides in muscle (8), heart (15), and immune cells (16); however, few studies have examined micropeptides in the context of the adult brain. Recent work in Drosophila has revealed that the sight of a parasite can induce micropeptide expression in the adult brain, driving mating behavior (17). Further, 
translation of some sORFs has been shown to be upregulated in the brain with aging (18). We therefore asked whether micropeptides may contribute to age-dependent psychiatric disease associated with 22q11.2DS.

Recently, our laboratory described a novel sORF in the 22q11.2 disease-critical region that is conserved between mouse and human (19). The Plasticity $\underline{\text { Associated }}$ Neural Transcript Short (Pants) is upregulated at both the transcript and protein level in the hippocampus during early adult aging in the mouse. The age-dependent increase in Pants is particularly notable in the stratum lucidum, which houses the mossy fiber (MF) connections from the dentate gyrus to the region CA3 structurally-complex dendritic spines, known as thorny excrescences. Here, we show that the Pants peptide is localized both intracellularly at synapses and secreted into the extracellular space around synapses. We further show that Pants mutation exerts an agedependent, overdominant, negative effect on synaptic plasticity at mossy fiber synapses. An endogenous proximity labeling screen revealed that Pants interacts with multiple intra- and extracellular proteins associated with memory and plasticity, including the Rtn4/Nogo-A protein.

previously been associated with SZ. Extracellular Pants at synapses quickly degrades with neuronal activity, resulting in increased AMPA receptor clustering. We therefore hypothesize that Pants is an adult-specific booster of Nogo-A signaling, repressing synaptic plasticity, and that activity-dependent degradation of Pants at select sites allows for plasticity at those synapses.

\section{Results}

\section{The Pants ${ }^{\text {SOG-Y }}$ transgenic mouse line to study endogenous Pants}

Previously, we showed in mice that Pants is expressed preferentially in areas CA3 and CA2 of the hippocampus, and that there is an upregulation of Pants peptide in these regions that 
is most prominent in the stratum lucidum between 8 and 16 weeks of age (19). However, as with other micropeptides studied (20), Pants is expressed at low levels and is poorly immunogenic, so antibody signal is low in most applications. In general, more traditional biochemical approaches to studying canonical proteins appear to be insufficient for tracking micropeptides. We therefore sought to verify our previous findings using a complementary, transgenic approach.

In order to obtain a more robust labeling of endogenous Pants, we used CRISPR/Cas9 to target the miniSOG and hemagglutinin (HA) tags to the C-terminus of the mouse Pants locus to generate a transgenic line that we refer to as Pants ${ }^{\text {SOG-Y }}$ (Fig. 1A). Primers flanking the tags were used to genotype founders (Fig.1B), and specific detection of the Pants-miniSOG-HA fusion protein (predicted MW 26.32 KDa), was verified by immunoprecipitation with antibodies to HA, followed by western blotting for the HA tag (Fig. 1C). Using this approach, we verified that Pants levels increase in hippocampus between 8 and 16 weeks of age. We observed a threefold increase in Pants protein at 16 weeks compared to 8 weeks (n=3, $P=0.004)$ (Fig1D).

Immunohistochemistry of 8- and 16-week-old Pants ${ }^{\text {SOG-Y }}$ brain sections with the HA antibody was consistent with previous findings that the Pants peptide is most highly expressed in areas CA2 and CA3 in the hippocampus, with very little detectable in dentate gyrus or CA1. Pants is found around cell bodies of the pyramidal cell layer, and throughout regions containing mostly neural processes. In agreement with previous data, Pants levels increase at 16 weeks, with the most notable increase in the stratum lucidum (Fig. 1E).

\section{Pants localizes to synapses in hippocampal neurons}

In order to study subcellular localization of Pants, we cultured primary neurons from Pants $^{+/+}$control and Pants ${ }^{\text {SOG-Y/+ }}$ transgenic animals. Staining of DIV18-21 neurons with an anti-HA antibody followed by confocal microscopy showed that Pants is found in a punctate pattern throughout neurons. Minimal background staining was observed in wildtype controls 
(Fig. 1F). Comparing Pants localization to that of the axonal marker Synapsin-1 and dendritic markers MAP2 and Shank-2 showed co-localization on both sides of the synapse (Fig. 1F and

2A-B). Using both confocal microscopy and structured illumination microscopy (SIM), we often detected Pants staining that was located near the synapse, but which did not fully overlap with either pre- or post-synaptic markers (Fig. 2A-B, red arrows). This led us to ask whether Pants may be secreted from neurons.

\section{Pants is secreted from Neuro2A cells and primary neurons}

SecretomeP 2.0 (21) predicts the Pants peptide to be non-classically secreted with an NNscore of 0.808. In order to test whether Pants is secreted, we overexpressed a Pants ${ }^{\text {SOG-Y }}$ fusion protein in the mouse neuroblastoma cell line Neuro2A (N2a). We collected proteins released into fresh media over a 30-minute period. We then separated cellular proteins from extracellular matrix (ECM)-bound proteins. After immunoprecipitation in lysates from each fraction with an HA antibody to concentrate our fusion protein, we immunoblotted for the presence of HA. As shown in Fig. C, Pants is found in cells, and is detectable in the media and ECM fractions of cells overexpressing the Pants ${ }^{\text {SOG-Y }}$ fusion protein. We next determined whether endogenous Pants might be released. To do this, we collected media from primary hippocampal neurons cultured from wild-type and Pants ${ }^{S O G-Y}$ mice. As shown in Fig. 2D, HA-Pants was detected in the culture media collected from Pants ${ }^{\text {SOG-Y }}$ neurons, but not from wild-type controls.

We next verified Pants secretion from neurons using an antibody feeding protocol that distinguishes extracellular from internal epitopes. This involves incubating live neurons with antibody to label extracellular epitopes prior to permeabilization and staining of intracellular proteins (22). As shown in Fig. 3A, internal and extracellular Pants show little overlap. Further, extracellular Pants shows little overlap with pre-synaptic and post-synaptic markers. Meanwhile, intracellular Pants shows more overlap with pre-synaptic Synapsin than post-synaptic 
MAP2/Shank2 markers. Fig. 3B shows internal and extracellular Pants at two types of synapses. The first is a classical mushroom spine, and the second is reminiscent of a maturing thorny excrescence. While CA3-CA3 connections occur on the former, the latter is the site in the intact hippocampus where DG-CA3 mossy fiber connections are formed. While we cannot draw analogies about the connectivity at these different spine types in culture, we observed both simple and complex spines in our cultured neurons. We observed a similar pattern of internal and extracellular Pants staining at both types of spines. An illustration of localization at each type of synapse is shown in Fig. 3C. Fig. 3D shows the quantification of overlap using Mander's colocalization coefficient in 190 spines for both internal and extracellular HA staining. As previously observed, intracellular Pants shows little overlap with extracellular staining, and overlapped more with presynaptic markers than postsynaptic markers. Meanwhile, the limited amount of extracellular Pants that does coincide with markers at all shows the most overlap with postsynaptic dendritic markers. Immunohistochemistry in adult hippocampus agreed with these results (fig. S2).

do this, we compared intracellular and extracellular Pants staining in primary neuron processes in the presence or absence of a brief (10 second) treatment with $60 \mathrm{mM} \mathrm{KCl}$, just prior to fixation and intracellular staining. We observed a striking 83.7\% reduction in extracellular Pants with $\mathrm{KCl}$ stimulation compared to unstimulated controls ( $\mathrm{n}=3 ; \mathrm{P}<0.001)$, and a $51.3 \%$ reduction in intracellular Pants (n=3, $\mathrm{P}=0.005)$.

\section{Pants is an age-dependent, overdominant, negative regulator of mossy fiber LTP.}

Deletion of the region on mouse chromosome 16 that is similar to human chromosome 22q11.2 results in an age-dependent augmentation of LTP at Schaffer collateral synapses. 
Because Pants shows such striking age-dependent up-regulation in stratum lucidum and is located in this disease-critical region, we asked whether loss of Pants affects mossy fiber LTP in acute hippocampal slices at 8 weeks (prior to the onset of symptoms in 22q11.2 model mice) and at 16 weeks (after symptom onset). At 8 weeks, in response to three $100 \mathrm{~Hz} / 1$ sec stimuli, we recorded indistinguishable LTP in area CA3 between Pants $^{+/+}$, Pants ${ }^{+/-}$, and Pants ${ }^{-/-}$mice (Fig. 4B)(n=6 mice/18 slices for Pants $^{+/+}, \mathrm{n}=10$ mice/30 slices for Pants ${ }^{+/-}, \mathrm{n}=5$ mice/15 slices for Pants $^{-/-}$; P $\left.>0.503\right)$. However, at 16 weeks, Pants $^{+/-}$slices showed a robust (277\%) increase in MF LTP, whereas Pants ${ }^{-/-}$LTP was indistinguishable from that of Pants ${ }^{+/+}$(Fig. 4C) (n=5 mice/18 slices for Pants ${ }^{+/+}, \mathrm{n}=5$ mice/18 slices for Pants ${ }^{+/-}, \mathrm{n}=5$ mice/19 slices for Pants ${ }^{-/}$.

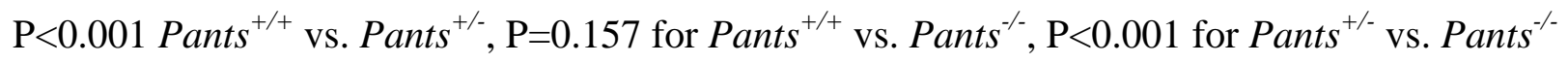

). We therefore conclude that Pants is an age-dependent, negative regulator of LTP, and that this effect is overdominant.

\section{Pants interacts with proteins important for plasticity, cognitive disease, and aging.}

In order to ascertain the molecular mechanism by which Pants inhibits synaptic function, proteomics approaches are suboptimal when studying small, low-expression, and transient proteins, as they require large amounts of protein and stable interactions. Further, lysis artifacts can occur when spatially separated proteins are mixed during cell homogenization. Because Pants appears to be highly dynamic in neuronal cells, we used a proximity-labeling approach, fusing endogenously-expressed Pants with a biotin ligase, which transfers biotin to proteins that come within nanometers of the fusion protein. This approach has the advantages that labeling occurs in intact cells or tissues, eliminating lysis artifacts and allowing for the sensitive capture of transient and low expression targets using the high-affinity interaction between biotin and streptavidin. 
The strategy for endogenous proximity labeling of Pants targets is outlined in Fig. 5A. We used the engineered biotin ligase TurboID, which is small (35 KDa) and has improved labeling kinetics over previous iterations of biotinylation enzymes (23). Using a similar strategy to that employed for the Pants ${ }^{\text {SOG-Y }}$ transgenic mouse line, we generated transgenic N2a cell lines in which V5-tagged-TurboID was fused to the C-terminus of the endogenous Pants locus. The TurboID coding sequence was followed by the t2A self-cleaving peptide and GFP, so that properly targeted cells could be selected using green fluorescence. After co-transfection of the sgRNA/Cas9, and the HDR plasmid, we sorted GFP-positive single cells into the wells of 96well plates. This allowed us to establish clonal cell lines to control for possible confounding results from Cas-9 off-targets. GFP-positive clones were expanded and genotyped for the correct targeting of TurboID to the Pants Locus (Fig. 5B). PCR products were then sequence verified. Western blotting of cell lysates using a V5-specific antibody showed a band of 48 KDa, the predicted size of the Pants-Turbo-ID fusion in the transgenic cell line, but not in control N2a cells (Fig. 5C). hours. Cells were collected and lysates were probed in western blots with a streptavidin antibody. As shown in Fig. 5D, N2a cells contain several endogenously biotinylated proteins, which likely correspond to mitochondrial carboxylases. In addition to these bands, samples from the Pants-Turbo transgenic cell lines contain additional, specific bands corresponding to Pantsinteracting proteins. These specific bands were reproducible in multiple clonal cell lines, despite the high background of biotinylated proteins and low labeling due to the use of endogenous Pants. Next, we used streptavidin beads to capture biotinylated protein, and identified captured proteins by Mass Spectrometry ( $\mathrm{n}=5$ N2a control and 5 Pants-Turbo Tg samples). As expected, 
the most-represented proteins in the control cell line were carboxylases, which are known to be biotinylated (table S3).

Table S2 and table S4 show proteomic hits that were specifically captured in the PantsTurboID cell line as compared to non-transgenic controls. As expected, the list is short, due to the above constraints. Localization data for proteomic hits from the UniProt database is summarized in Fig. 5E. The groups most represented are cytosolic and extracellular/transmembrane. This aligns with our imaging findings that Pants is both cytosolic and extracellular. Additionally, there were targets identified in ER and Golgi, which would be predicted for a secreted protein. IPA function analysis identified a number of proteins in the dataset associated with SZ, with the most functional connections between the proteins Ncam1 and Nogo-A. (Fig. 5G).

As highlighted in table S2 and Fig. 5F, many of the Pants-binding proteins identified in this screen have been implicated in either plasticity or memory, including Ncam-1, $\alpha$-internexin, Rtn4/Nogo, Stim1, Stathmin2 and Akap 12. In addition, a number of these proteins have been implicated in diseases of cognition.

To verify the hits from our proteomics screen, we performed biotin labeling experiments in a separate clonal Pants-Turbo transgenic cell line, and performed western blots on streptavidin-captured proteins, immunoblotting with commercial antibodies to selected protein hits from the screen. As shown in Fig. 5H, many of these proteins were verified to be specifically biotinylated in the Pants-TurboID line as compared to N2A controls. $\beta$-Actin was used as a negative control, and did not become biotinylated in the Pants-TurboID cells, whereas V5 labeling is prominent in this sample, indicating that Pants itself becomes biotinylated by TurboID. For each of the proteins tested, biotinylation occurred specifically in the Pants-Turbo sample, but not in N2a controls. Proteins verified included Rtn4/Nogo, Ncam-1, Ranbp2, and 
Cct8. In the case of NCam-1, we detected two of its isoforms, Ncam-140 and Ncam-180 in lysates; however, the Pants-TurboID transgene specifically led to biotinylation of the NCam-180 isoform (Fig 5H). This isoform is almost exclusively postsynaptic (24), and increases in spines following LTP induction in the perforant pathway (25), but it is not found at MF synapses (24). Thus, the interaction between Pants and Ncam-180 is likely not important for the plasticity effect of Pants at MF synapses. The 120KDa polysialated form of Ncam-1was not detected by our antibody, but it is important for hippocampal plasticity (26) and remains an important candidate. Rtn4/Nogo was an especially compelling hit from this proteomics screen for several reasons. First, like the 22q11.2 locus that includes Pants, the 2p16 genomic region that contains the Rtn4 gene is a susceptibility locus for schizophrenia $(27,28)$. Additionally, the gene encoding one of its many receptors, $R \operatorname{tn} 4 R$, is localized to the 22q11.2 region. In organotypic slices, Nogo-A acts specifically on the structure and function of area CA3 of the hippocampus, where Pants is most highly expressed in adults. Nogo-A is well known for its role in axon guidance in the developing nervous system (29); however, in the adult nervous system, Nogo-A phenocopies Pants, acting as a negative regulator of synaptic plasticity. Particularly intriguing is the finding that the Nogo-A knockout has no effect on plasticity, whereas blockade with antibodies in acute murine slices (30) or knockdown with a miRNA approach in rats (31) results in an increase in LTP at Schaffer collateral synapses. This striking similarity with the Pants overdominant LTP increase lead us to question whether Pants may affect Nogo-A function at synapses.

To test this, we first asked whether Pants and Nogo-A interact at synapses. We cultured hippocampal neurons from Pants ${ }^{S O G-Y}$ transgenic mice, and co-stained with antibodies to HA and Nogo. We observed significant overlap of Pants and Nogo at selected synaptic sites (Fig. 6A). This led us to wonder whether the interaction of Pants and Nogo may stabilize Nogo-A's 
downstream signaling pathways. The synaptic impact of Nogo-A is well-studied, and is summarized in Fig. 6D. The extensive extracellular domain of Nogo-A is divided into subdomains, each of which has been shown to interact with specific receptors. For example, the Nogo-66 domain interacts with a number of proteins, including Rtn4R (32). These interactions activate the RhoA pathway, stabilizing local actin dynamics in spines, thus blocking structural aspects of plasticity. The $\Delta 20$ domain is a disordered domain at the N-terminus of the Nogo-A protein that interacts with the Sphingolpid receptor S1Pr2, and it is this interaction that has been shown to dictate Nogo-A’s suppression of functional plasticity (33). Multiple laboratories have provided evidence that Nogo-A signaling through its receptors can affect receptor clustering at postsynaptic sites (34-36). We therefore hypothesized that Pants may structurally stabilize the Nogo-A interaction with receptors, to modulate postsynaptic AMPA-receptor clustering. To test this, we labeled membrane-localized GluR1 AMPA receptors by feeding a GluR1 antibody specific to an extracellular epitope, and measured AMPA fluorescence in spine membranes before and after $\mathrm{KCl}$ stimulation. With no $\mathrm{KCl}$ treatment, there is no clear relationship between Pants co-localization with Nogo-A and AMPA receptors (fig. S3). However, after KCl stimulation, when extracellular Pants rapidly degrades, there is a strong negative correlation between co-localization of the remaining Pants with Nogo-A and AMPA fluorescence. That is, synapses where Pants remained were associated with less membrane AMPA fluorescence than synapses lacking Pants associated with Nogo-A (Fig. 6B). We did not observe a similar effect for intracellular Pants (fig S3). We therefore conclude that Pants interaction with Nogo-A poststimulus inhibits those synapses, whereas the rapid degradation of extracellular Pants at other sites creates a permissive environment for plasticity to occur.

\section{Discussion}


While the juvenile brain is highly permissive to plasticity, the adult brain develops multiple mechanisms to gate plasticity, making the adult brain a more discerning network. For example, ECM remodeling from adolescence into adulthood plays a plasticity-dampening role in the adult brain (37). Negative regulators of plasticity induction, such as Nogo-A pathway members, are altered with age, and these expression changes are associated with cognitive resilience in aged animals (38-40). Structural plasticity at spines has also been shown to change with age (41). Complex structural changes such as these are energetically costly for already taxed, aging neurons. Here we describe a mechanism by which the brain employs a micropeptide to rapidly modulate larger signaling complexes at the synapse. Micropeptides therefore represent a comparatively low-energy way for the brain to gate synaptic exchanges without the costly remodeling of larger protein complexes.

The overdominant effect of Pants on plasticity at MF synapses is particularly intriguing. Due to the low expression level of Pants, there is likely stoichiometric competition for Pants binding. Although Nogo-A is a negative regulator of plasticity, other proteins found bound to Pants, such as Ncam-1, have opposite effects on plasticity when blocked. Therefore, if Pants is partially reduced, the remaining Pants may preferentially bind and modulate targets that positively regulate plasticity, with the net effect being relief of Nogo-A restrictions on plasticity, whereas complete loss of Pants may further modulate these positive regulators, resulting in a balance of negative and positive effects of Pants target proteins. Further study of this phenomenon is ongoing in the lab.

The Pants interactome indicates functions for Pants in multiple subregions of neurons and synapses, but also potentially in other brain regions. For example, Vat1L is a marker for von Economo neurons (VENs) (42), which are most highly concentrated in socio-emotional cortical areas of human and closely-related primate brains. VENs show high expression of the DISC1 
schizophrenia-associated gene (43), and the number of VENs is correlated with schizophrenia age of onset (44). This study confirms the importance of pursuing the human isoforms of Pants in both hippocampus and cortex.

The presence of micropeptides in the synaptic cleft represents a new frontier for neuropharmacology. While the major receptor systems targeted by more traditional therapeutics are pervasive throughout the brain, micropeptides may be employed in a more spatially and temporally restricted manner. Further study of these elements in normal health and disease therefore provides the potential for safer, more effective therapies.

\section{Materials and Methods}

\section{Animals}

Young (6-8 weeks) and mature (16-20 weeks) mice and their respective wild-type littermates of both sexes were used. Mice were generated and maintained on the C57BL/6 genetic background. Pants $^{+/-}$mice were generated by KOMP (https://www.komp.org), using a velocigene targeting vector to disrupt the gene just downstream of the start codon. Mice were then crossed with EIIacre mice (Jackson Labs) expressing a germline specific Cre recombinase to delete the Neomycin cassette. Mice were genotyped using the following primers: PantsWTF: accatgtgaatctactgcctgaggg, PantsWTR: tatgtgggtgaatgcctgtagtcce, and PantsMF: gctcacctacactctgtgtatg and LacZR: gtgtagatgggcgcatcgtaac. PCR was performed using Go Green Taq (Promega) according to the vendor protocol. Cycling parameters were: 98oC 3min, followed by 35 cycles of $98^{\circ} \mathrm{C} 30$ seconds, $53^{\circ} \mathrm{C} 30$ seconds, $72^{\circ} \mathrm{C} 30$ seconds, and a final $72^{\circ} \mathrm{C}$ extension for 5 minutes. This protocol produces a wildtype amplicon of $341 \mathrm{bp}$ and a mutant amplicon of 718bp. Pants ${ }^{\text {SOG-Y }}$ mice were generated using the Alt-R CRISPR-Cas9 crRNA kit (Integrated DNA Technologies), following the manufacturer's protocol. Briefly, the crRNA 
sequence (5’ gggaggttccagtccgtaggggg 3’) was designed to target the area proximal to the stop codon in the Pants coding region using CHOPCHOP version 3 (45). This crRNA was duplexed with trans-activating crRNA (tracrRNA) and mixed with Alt-R S.p. HiFi Cas9 Nuclease (IDT) to form a ribonucloprotein complex. Complexes were electroporated into C57BL/6 zygotes with a

double stranded donor DNA sequence. This dsDNA contained 1kb of homology upstream of the crRNA target sequence, the miniSOG and HA sequence added to the coding region of Pants just before the stop codon, followed by $1 \mathrm{~kb}$ of downstream homology. Viable electroporated embryos at the two-cell stage were transferred to pseudopregnant females to create Pants ${ }^{\text {SOG-Y }}$ founders. Two positive males and two positive females were identified by genotyping and backcrossed with C57BL/6 mice to generate F1 mice. Primers used for genotyping were 5’ tgctcagaagcacaccttgg 3’ (forward) and 5’ aattagggctggaaatgctttgc 3’ (reverse) for the WT reaction and 5' tgtgctaaaacagaacagttgcc 3' (forward) and 5’ gaggttccagaatttcttcc 3' (reverse) for the mutant reaction. PCR was performed using GoTaq Green (Promega) according to the vendor protocol. Cycling parameters were $98^{\circ} \mathrm{C} 3 \mathrm{~min}$, followed by 35 cycles of $98^{\circ} \mathrm{C} 30$ seconds, $48^{\circ} \mathrm{C}$ for Mut reaction or $59^{\circ} \mathrm{C}$ for WT reaction 30 seconds, $72^{\circ} \mathrm{C} 30$ seconds, followed by a final extension of $72^{\circ} \mathrm{C}$ for 5 mins. Genotyping reactions result in a $176 \mathrm{bp}$ amplicon for the WT allele and a 569bp amplicon for the mutant allele. The care and use of animals were reviewed and approved by the Institutional Animal Care and Use Committee of Tulane University.

\section{Plasmid construction}

To generate the donor DNA sequence used in the generation of the Pants ${ }^{\text {SOG-Y }}$ mice, the upstream and downstream homology arms were amplified from mouse cDNA, adding the NheI and XbaI restriction sites for the upstream homology region using primers 5' 
tatgctagctggcctggaactcagaaatcc 3’and 5’ tatctagacttgtccttctcctgtggtagagggaggttccaatcagtaggggg

3.’ XhoI and HindIII sites were introduced for the downstream homology region using primers, 5' tatctcgagtaagcaactgcaacctacc 3' and 5' ataaagcttaaaatacattaacaatgagg 3'. PCR products were digested, gel purified, and ligated into pcDNA3.1(-). The miniSOG-HA sequence was amplified from the miniSOG-C1 plasmid, introducing XbaI and XhoI sites using primers, 5’ tattctagaatggagaaaagttcgtgataac 3' and 5' atactcgagtcaagcgtaatctggaacatcgtatgggtaaccaccaccaccacctccatccagctgcactccg 3', digested and ligated into pcDNA3.1(-), between the XbaI and XhoI sites of the homology arms. MiniSOG-C1 was a gift from Michael Davidson (Addgene plasmid \#54821 ; http://n2t.net/addgene:54821 ; RRID:Addgene_54821). We modified the serine and arginine amino acids introduced by adding the XbaI site to an alanine and a glycine using the NEB Q5 Site-Directed Mutagenesis Kit (E0554S) altering the restriction site sequence from 5' tctaga 3' to 5' gctgga 3' (primers used were 5' ccacaggagaaggacaaggctggaatggagaaaagtttcgtg 3' and 5' cacgaaacttttctccatggcggccgccttgtccttctcctgtgg 3’). To purify dsDNA fragment for electroporation, the newly generated plasmid was digested with NheI and HindIII to release the donor sequence and the fragment was purified using the Qiagen QIAEX II gel extraction kit.

To generate the plasmids used for the TurboID transgenic cell line generation, we introduced a NotI cloning site into the Pants homology plasmid described above, using sitedirected mutagenesis and the following primers: 5' ccacaggagaaggacaaggcggcggccgccatggagaaaagtttcgtg 3’ and 5' cacgaaactttctccatggcggccgcttgtccttctcctgtgg 3'. The miniSOG-HA sequence was digested out of the plasmid with NotI and XhoI, and V5-TurboID-t2A-EGFP sequence, amplified from the V5-TurboID-NES_pCDNA3 plasmid (Ting Lab, Addgene plasmid \#107169 ; http://n2t.net/addgene:107169 ; RRID:Addgene_107169), was ligated into these sites. For in 
vitro expression of sgRNA and Cas9, we cloned the same sgRNA sequence from the generation of the Pants ${ }^{\text {SOG-Y }}$ mouse line into the pX330-U6-Chimeric_BB-CBh-hSpCas9, a gift from Feng Zhang (Addgene plasmid \#42230 ; http://n2t.net/addgene:42230 ; RRID:Addgene_42230).

The Pants ${ }^{\text {SOG-Y }}$ overexpression (OE) plasmid was generated by amplifying the coding sequence for Pants from mouse cDNA using 5’ tatgctagcgccaccatggcggtcgcagggagc 3’ and 5’ tattctagatcacttgtccttctcctgtgg 3' to introduce NheI and XbaI. The digested amplicon was fused to the miniSOG-HA sequence, amplified again from the miniSOG-C1 plasmid using the same primers used to clone miniSOG above. This full sequence was ligated into pcDNA3.1(-) to use for in vitro overexpression by transfection into N2a cells.

N2A and transgenic cell lines were cultured in DMEM medium (SH30243, Cytiva) supplemented with 10\% FBS (R\&D Systems), GlutaMAX (Fisher Scientific), and Penicillin/Strepomycin (15140-122, Gibco). V5-TurboID-t2A-GFP was knocked into the endogenous Pants locus of Neuro2A cells by transfecting the TurboID donor sequence plasmid along with the Pants ${ }^{\text {SOG-Y }}$ sgRNA plasmid. 48 hours after transfection, single EGFP positive cells were sorted into the wells of a 96 well plate using a Sony SH800 cell sorter to obtain clonal cell lines. Cell lines that were positive for GFP were expanded and genotyped using PCR. Primers used for genotyping were 5' tgtgctaaaacagaacagttgccaa 3' (forward) and 5' aattagggctggaaatgctttgc 3’ (reverse) for the WT reaction and 5' tgctcagaagcacaccttgg 3’ (forward) and 5' ctcgagtctcaaccggtcttgtacagctcgtc 3' (reverse) for the mutant reaction. PCR was performed using GoTaq Green (Promega) according to the vendor protocol. Cycling parameters were $98^{\circ} \mathrm{C} 3 \mathrm{~min}$, followed by 35 cycles of $98^{\circ} \mathrm{C} 30$ seconds, $53^{\circ} \mathrm{C} 30$ seconds, $72^{\circ} \mathrm{C} 30$ seconds, followed by a final extension of $72^{\circ} \mathrm{C}$ for 5 mins. PCR products were sequenced to verify correct 
targeting of the Pants locus. The expression of the transgene was verified by the detection of a $48 \mathrm{KDa}$ band on a Western blot of cell lysates probed with an antibody to the V5 tag.

\section{Endogenous proximity labeling}

Neuro2a cells (negative control) and Pants-TurboID N2a cells were grown to 90\% confluency on $150 \mathrm{~mm}$ cell culture dishes. Biotin $(100 \mathrm{mM})$ in DMSO was added to a final concentration of $50 \square \mathrm{M}$ to all samples for 18 hours. After labeling, plates were placed on ice and washed 5 times in 10ml ice cold PBS. Cells were displaced by scraping in 5ml PBS, collected by centrifugation at 5,000g at $4 \circ \mathrm{C}$, and frozen at $-80{ }^{\circ} \mathrm{C}$. Cell pellets were lysed in RIPA buffer $(50 \mathrm{mM}$ Tris- $\mathrm{HCl}$ pH 7.5, 150mM NaCl, 1\% Triton, 0.1\% SDS, 0.5\% Sodium Deoxycholate) with protease inhibitors (78428, ThermoFisherSci), and protein was quantified using a Protein 660 assay (22660, ThermoFisherSci). 2-4mg protein was added to $350 \square 1$ streptavidin beads, and Streptavidin pulldown continued as previously described (46). For proteomics, beads were washed an additional 3 times with 1ml Tris-buffered saline to remove detergents, prior to onbead trypsinization.

\section{On-Bead Trypsinization of biotinylated proteins}

The procedure was adapted from (23). After several washes in 50mM Tris, pH 7.5 containing 2M Urea, beads and bound biotinylated proteins were incubated with $0.5 \mathrm{ug}$ trypsin in $50 \mathrm{mM}$ Tris, $\mathrm{pH}$ 7.5/2M Urea for 1 hour with shaking. This step was repeated for a second 15-minute period. These supernatants were pooled, the cysteines were reduced during a 1 hour incubation with $2 \mathrm{ul}$ of 500mM Tris(2-carboxyethyl)phosphine, and subsequently alkylated with a 30-minute incubation with $5 \mathrm{ul}$ of $375 \mathrm{mM}$ iodoacetamide in the dark. An additional 0.5ug of trypsin was added for an overnight incubation at room temperature. 
The next day, samples were acidified by the addition of trifluoroacetic acid until $0.5 \%$, and then trypsinized peptides were purified using C18 tips (Thermo). The eluted peptides were dried to completion until ready for LC-MS analysis.

\section{Liquid Chromatography-Mass Spectrometry (LC-MS)}

The samples were run on a Dionex U3000 nano flow system coupled to a Thermo Fusion mass spectrometer. Each sample was subjected to a 90-minute chromatographic method employing a gradient from 2-50\% acetonitrile in $0.1 \%$ formic Acid (ACN/FA) over the course of 65 minutes, from 50 to $99 \%$ ACN/FA for an additional 10 minutes, a hold step at 90\% ACN/FA for 4 minutes and a re-equilibration into 2\% ACN/FA. Chromatography was carried out in a "trapand the separation column was EasySpray PepMap RSLC C18, 2um, 100A, 25cm. The entire run was $0.3 \mathrm{ul} / \mathrm{min}$ flow rate. Electrospray was achieved at $1.9 \mathrm{kV}$

MS1 scans were performed in the Orbitrap utilizing a resolution of 240,000, and data dependent MS2 scans were performed in the Orbitrap using high energy collision dissociation (HCD) of $30 \%$ using a resolution of 30,000 (47).

Data analysis was performed using Proteome Discoverer 2.4 using SEQUEST HT scoring. The background proteome was Mus musculus (SwissProt TaxID 10090, version 2017-10-15, downloaded on 01/19/2018). Static modification included carbamidomethyl on cysteines (=57.021), and dynamic modification of methionine oxidation (=15.9949), and biotinylation of N-termini and lysines (+226.0776). Parent ion tolerance was 10ppm, fragment mass tolerance was $0.02 \mathrm{Da}$, and the maximum number of missed cleavages was set to 2. Only high scoring peptides were considered utilizing a false discovery rate (FDR) of 1\%. Results were reported on grouped-replicate sample files and compared to identically treated control samples.

\section{Western blotting}


Mice were sacrificed by decapitation, and hippocampi were dissected in cold PBS, frozen on dry ice and then stored at $-80 \circ \mathrm{C}$. Lysates were prepared by needle passage in RIPA buffer containing protease inhibitors, followed by brief sonication. Lysates were clarified by centrifugation at $13,000 \mathrm{~g}$ for 10 minutes at $4 \circ \mathrm{C}$. Protein concentrations were determined by a protein 660 Assay, diluted to equal concentration in sample buffer, and stored at $-80{ }^{\circ} \mathrm{C}$. Proteins were resolved on Novex 10-20\% Tris-Glycine gels (Invitrogen, Carlsbad, CA) via SDS-PAGE and transferred to PVDF membranes (Invitrogen, Carlsbad, CA) according to manufacturer recommendations. Membranes were blocked with 3\% BSA in TBST for 30 minutes at room temperature. Primary antibodies described in table S1 were diluted in blocking buffer and incubated overnight at $4^{\circ} \mathrm{C}$ with gentle agitation. Membrane was washed 3x for 10 minutes in TBST. Secondary antibodies, goat anti-rabbit IgG IRDye 650 (1:10,000, LI-COR, Lincoln, NE) and donkey anti-mouse IRDye 800CW (1:15,000) were diluted in blocking buffer (LI-COR, Lincoln, NE) and incubated at room temperature in the dark on a shaker for 60 minutes. Membrane was washed 3x 10 minutes in TBST and then scanned on a LI-COR Odyssey scanner. To verify specificity of labeling in Pants-Turbo cell lines, 40-50 micrograms of total cell protein was separated by SDS-PAGE gel electrophoresis, blocked overnight, and incubated with a steptavidin-horse radish peroxidase antibody $(0.3$ micrograms $/ \mathrm{ml})$ for 1 hour prior to washing in TBST and ECL. To verify proteomic hits, labeled proteins were eluted from streptavidin beads by boiling for 10 minutes in SDS sample buffer containing 20mM DTT and 2mM biotin. Samples were separated by SDS-PAGE and subjected to western blotting using antibodies specific to proteins identified in the proteomics screen. All western blots proceeded as described above, with the exception of Ranbp2, the antibody for which required blocking and antibody incubation in 5\% non-fat dry milk in TBST.

\section{Immunohistochemistry}


Fixed, cryoprotected, and OCT (VWR, Radnor, PA) embedded tissue was sectioned coronally at 25 $\mu$ m using a Leica CM3050S cryostat (Leica, Wetzlar, Germany). All tissue was then processed as follows. Tissue was permeabilized in 0.3\% Triton X-100/1\% BSA (Sigma, St Louis, MO)/1xPBS for 1 hour, washed in 1xPBS, and incubated with primary antibodies in $0.3 \%$ Triton X-100/1\% BSA/PBS at $4^{\circ} \mathrm{C}$ overnight. Sections were washed 3x 5 minutes in $1 \mathrm{xPBS}$ and then incubated with secondary antibodies for 1 hour at room temperature. Secondary antibodies included donkey anti-rabbit AlexaFluor 488 (1:1,000; Life Technologies, Eugene, OR), goat anti-mouse AlexaFluor 568 (1:1,000; Life Technologies, Eugene, OR), and Hoeschst (ThermoFisher). Sections were washed again 3x 5 minutes in 1xPBS and mounted with Fluoromount-G (SouthernBiotech). Tissue or cells lacking the SOG-Y transgene were used as a negative control. Images were obtained with a 10x or 20x objective on a Nikon A1 confocal microscope.

\section{Primary culture of hippocampal neurons}

Neuronal cultures were obtained from postnatal day 0 (P0) to P2 C57BL/6 mouse hippocampi from both sexes. Hippocampi were removed and digested with papain (2mg/mL, Worthington) in Hibernate without Calcium (BrainBits) and $0.1 \%$ DNase at $37^{\circ} \mathrm{C}$ for 10 minutes. Following titration of tissue by sterile Pasteur pipet, dissociated cells were re-suspended in culture media (Neurobasal A media (ThermoFisherSci) supplemented with GlutaMAX, pen-strep, B27, 1mM HEPES, and $10 \%$ horse serum) and plated at 30,000 cells $/ \mathrm{cm}^{2}$ on poly-d-lysine and laminin 20 coated dishes. Cells were maintained in feeding media (Neurobasal A media (ThermoFisher) supplemented with GlutaMAX, pen-strep, B27, and 1mM HEPES) by half media changes every 3-4 days until DIV14-21. Cultures were incubated at $37^{\circ} \mathrm{C}, 5 \% \mathrm{CO}^{2}$ and $95 \%$ relative humidity.

\section{Immunocytochemistry}


Cultured cells were fixed in 4\% PFA for 10mins and washed 3x with PBS. Followed by blocking in $0.3 \%$ Triton X-100/5\% BSA in PBS for 1 hour. Cells were then incubated in primary antibody overnight at $4^{\circ} \mathrm{C}$ with agitation. The next day, cells were washed $3 x$ with PBS and incubated with secondary antibodies for 1 hour at room temperature. Cells were washed again 3x with PBS before allowing to dry and mounting with Fluoromount-G (SouthernBioTech). Differential labeling of intracellular and extracellular HA epitopes protocol was adapted from (22). Briefly, the mouse anti-HA antibody (Santa Cruz) was added to primary neuron media and incubated for 2 hours at $37^{\circ} \mathrm{C}$ to allow for primary antibody binding to extracellular epitopes. Neurons were then fixed in 4\% PFA for 5mins at room temperature followed by $3 \mathrm{X}$ washes with PBS. Cells were then blocked for 30mins with 5\% BSA in PBS at room temperature. A fluorescently labeled secondary antibody (donkey anti-mouse 488, Invitrogen) was then applied to neurons for 1 hour to specifically label the extracellular HA epitopes. Any protein that was internalized after primary antibody binding would not be labeled with this secondary. Cells were then washed 3x with PBS. Further blocking was conducted on unpermeabilized neurons by incubation with an unlabeled AffiniPure $F_{a b}$ fragment Donkey anti-Mouse IgG $(\mathrm{H}+\mathrm{L})$ (Jackson ImmunoResearch) at $0.13 \mathrm{mg} / \mathrm{mL}$ overnight at $4^{\circ} \mathrm{C}$. The next day, neurons were washed $3 x 5 \mathrm{~min}$ with PBS followed by a post-fix in 4\% PFA in PBS for $5 \mathrm{~min}$ at room temperature. After $2 \mathrm{X}$ 5min washes with PBS to remove the fixative, neurons were permeabilized and blocked in 5\%BSA in PBS with 0.1\% Triton-X-100 for 30mins at room temperature. Permeabilized neurons were then incubated in primary antibody solutions overnight at $4^{\circ} \mathrm{C}$ with agitation. The mouse anti-HA antibody was not introduced to the neurons again during this incubation. The next day, neurons were washed 3x 5mins in PBS before incubation with secondary antibodies for 1 hour at room temperature. This incubation included a 405-conjugated donkey anti-mouse secondary antibody to differentially label the intracellular HA epitopes. Neurons were washed for a final 3x 
5mins in PBS before mounting with Fluoromount-G (SouthernBioTech) and allowed to cure overnight at $4 \circ \mathrm{C}$ before imaging with a Nikon $\mathrm{C} 1$ confocal microscope with $60 \mathrm{X}$ objective.

\section{Electrophysiology}

400 micron acute, transverse hippocampal slices were prepared in cold dissection buffer

$\mathrm{NaHCO}_{3}$, and 20mM glucose (285-295mOsm)) as previously described (6). Slices recovered for 1hour in ACSF (125mM NaCl, 2.5mM KCl, 2mM CaCl $2,2 \mathrm{mM} \mathrm{MgCl}_{2}, 1.25 \mathrm{mM} \mathrm{NaH}_{2} \mathrm{PO}_{4}$, 26mM NaHCO 3 , and 10mM glucose) and were continuously superfused with warm ACSF (30$32 \circ \mathrm{C}$ ) at a rate of $2-3 \mathrm{ml} / \mathrm{minute}$ for recording. All solutions were equilibrated by continuous bubbling with $95 \% \mathrm{O}_{2} / 5 \% \mathrm{CO}_{2}$. Field EPSPs were recorded from the stratum lucidum in area CA3 using an extracellular glass pipette with a resistance of 3-5M $\Omega$ filled with ACSF. Mossy fibers were stimulated with a bipolar tungsten electrode placed in the granule cell layer of the dentate gyrus (Fig. 4A). Stimulation intensities were chosen to produce a fEPSP of 30\% of maximium reponse. Baseline was monitored for 20 minutes, prior to LTP induction by three, 1second trains of $100 \mathrm{~Hz}$, delivered at an interval of 10 seconds (48).

\section{Enzymatic degradation of ECM}

100 micron acute, transverse hippocampal slices were obtained as above. Slices were incubated in recording aCSF with 0.2U/mL chABC (C3667, Sigma-Aldrich) or control recording aCSF for 1 hour at $37{ }^{\circ} \mathrm{C}$ with agitation. After 1 hour, slices were fixed in $4 \%$ PFA for $10 \mathrm{~min}$ and washed

3x in PBS. Slices were mounted on slides and processed using IHC methods described above.

WFA lectin (L-1516, Sigma-Aldrich) staining was used to monitor the extent of ECM degradation.

\section{In vitro $\mathrm{ECM}$ analysis}


Detection of Pants ${ }^{\text {SOG-Y }}$ protein in media, cell bodies, and ECM was adapted from a previously established protocol (49). N2a cells were transfected with the Pants ${ }^{\text {SOG-Y }}$ overexpression plasmid and allowed to grow for 48 hours. Media on cells was completely exchanged for serum free media, 30 mins before harvesting. Serum free media from overexpression and untransfected control cells was collected and proteins were later precipitated using trichloroacetic acid (TCA). In brief, 0.11 volumes of ice cold 100\% TCA was added to protein samples and incubated on ice for 20 minutes. After incubation, samples were spun at $14.8 \mathrm{xg}$ for 10 minutes at $4^{\circ} \mathrm{C}$. Supernatants were removed and pellets were washed with ice cold 100\% acetone and recentrifuged. Supernatant was again removed and pellets were allowed to dry on ice for 10 minutes. Protein pellets were reconstituted in RIPA buffer. To specifically detach cell bodies from ECM, 20mM ammonium hydroxide was added to culture dishes and allowed to incubate for 5 mins at room temperature with gentle agitation once per minute. Cell body material was later TCA-precipitated by using the same method described for media fractions. To harvest ECM, culture dishes were washed $3 \mathrm{x}$ with de-ionized $\mathrm{H}_{2} \mathrm{O}$, and the absence of remaining cells was confirmed under a microscope prior to mechanically lifting ECM material from the dish in RIPA using a cell scraper. All three fractions for overexpression and untransfected cells were immunoprecipitated using anti-HA magnetic beads (ThermoFisherSci) and the presence of HAPants was confirmed by Western blot.

\section{Imaging and Statistical Analysis}

PClamp (Version10.6, Axon Instruments) was used for acquisition and analysis of fEPSPs. All confocal images were run through denoise and deconvolution processing in Nikon Elements software version 5.30.03. Elements was also used for colocalization analysis on selected ROIs in 
bioRxiv preprint doi: https://doi.org/10.1101/2022.01.26.477857; this version posted January 28,2022 . The copyright holder for this preprint (which was not certified by peer review) is the author/funder, who has granted bioRxiv a license to display the preprint in perpetuity. It is made available under aCC-BY-NC-ND 4.0 International license.

intra/extracellular HA labeling experiments in neurons. All statistical analysis for confocal images and electrophysiology data was done in SigmaPlot (Version 13.0, Systat Software Inc.).

(1)

\section{Figures}




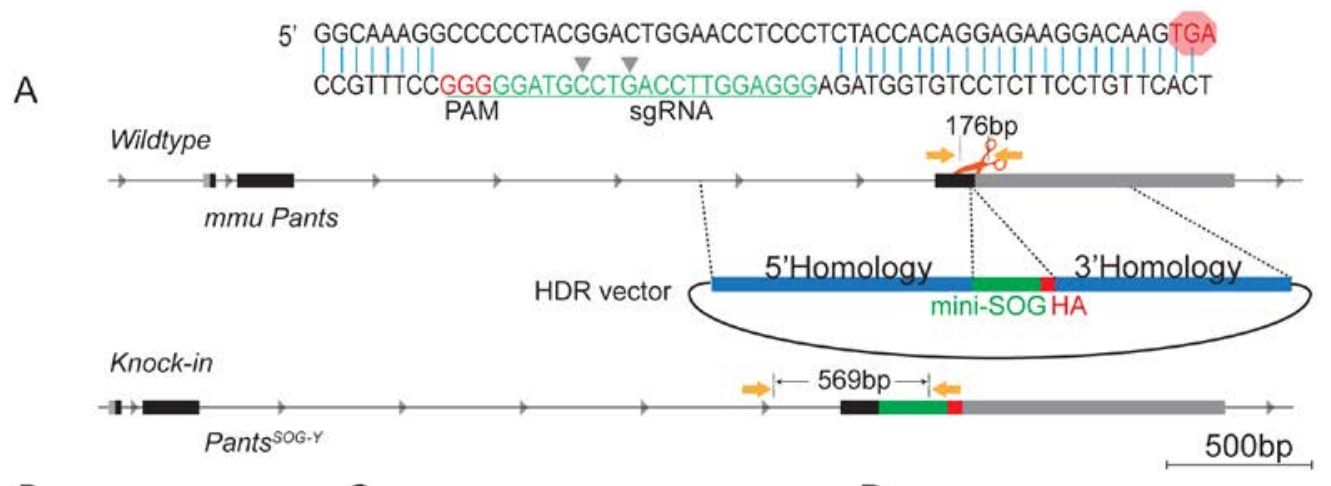

B

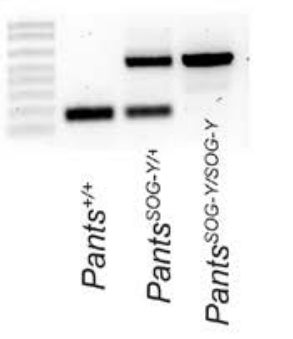

$\mathrm{E}$
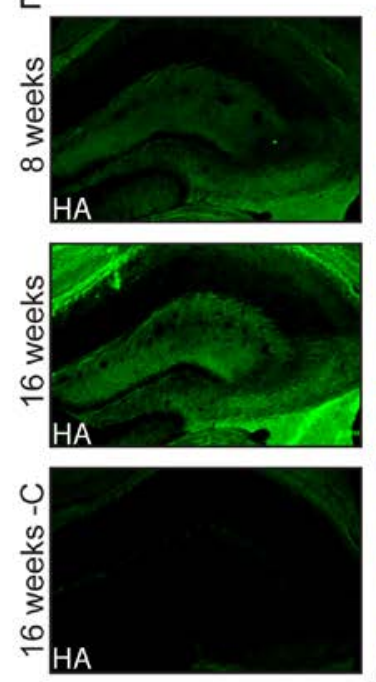

C

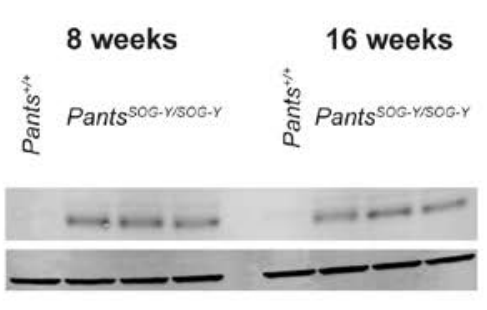

D
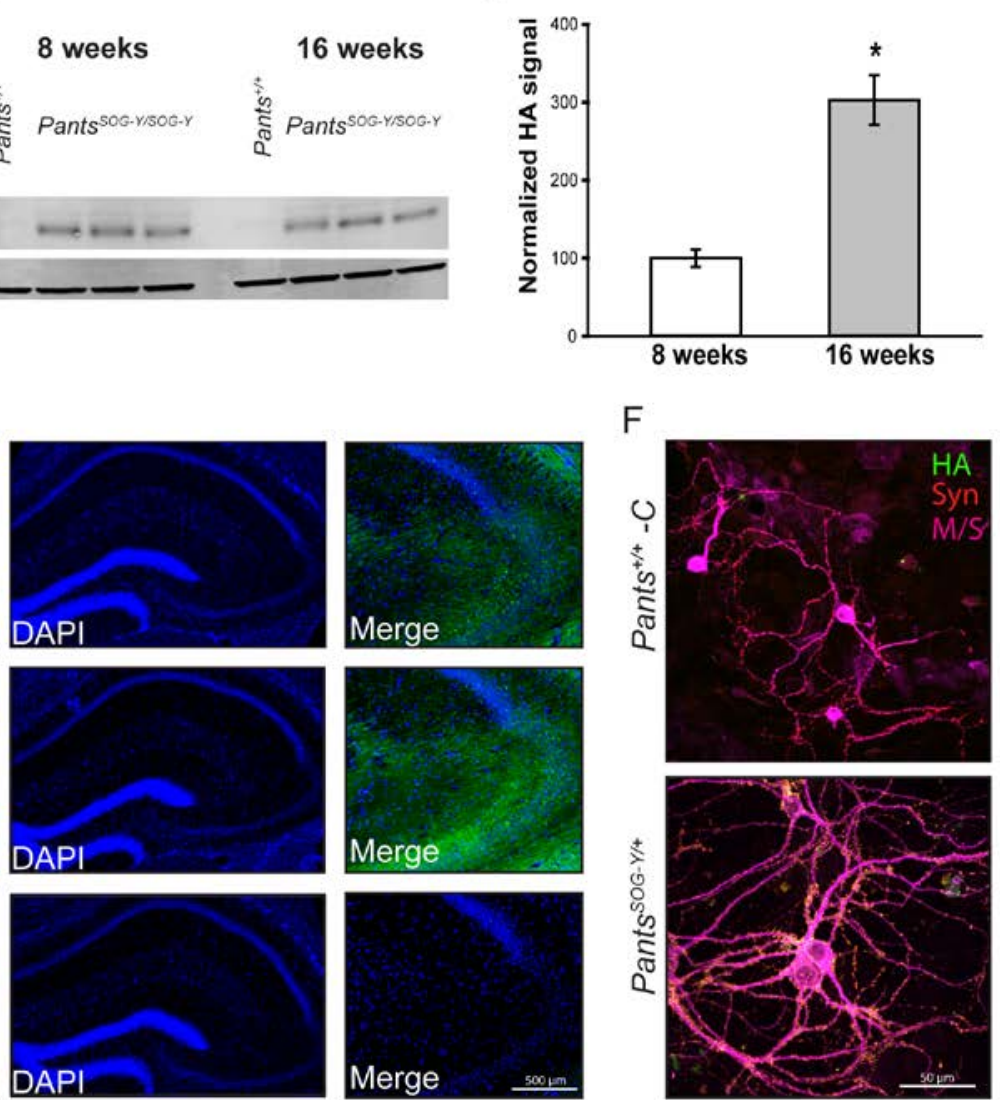

$\mathrm{F}$
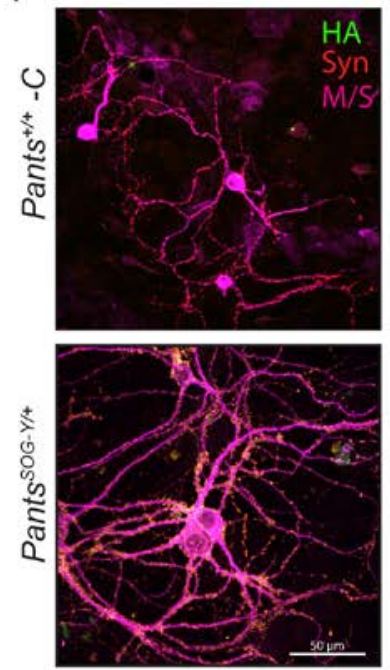

Fig. 1: Generation and characterization of a transgenic mouse line to study endogenous

Pants. a) CRISPR/Cas9 strategy to target the miniSOG and HA tags to the C-terminus of the endogenous Pants locus. b) Genotyping verification of insert in mouse tail biopsies. c) Quantitative Western blot of Pants immunoprecipitated from hippocampus of Pants ${ }^{S O G-Y}$ mice at 8 and 16 weeks immunoblotted with HA antibody. d) Quantification of Western blot bands from (c). e) Immunohistochemistry with HA antibody shows Pants localization in the hippocampus at 
bioRxiv preprint doi: https://doi.org/10.1101/2022.01.26.477857; this version posted January 28, 2022. The copyright holder for this preprint (which was not certified by peer review) is the author/funder, who has granted bioRxiv a license to display the preprint in perpetuity. It is made available under aCC-BY-NC-ND 4.0 International license.

8 and 16 weeks. f) Immunocytochemistry with HA antibody shows Pants localization throughout cultured hippocampal neurons from Pants ${ }^{\mathrm{SOG}-\mathrm{Y} /+}$ mice, but not wildtype controls. 


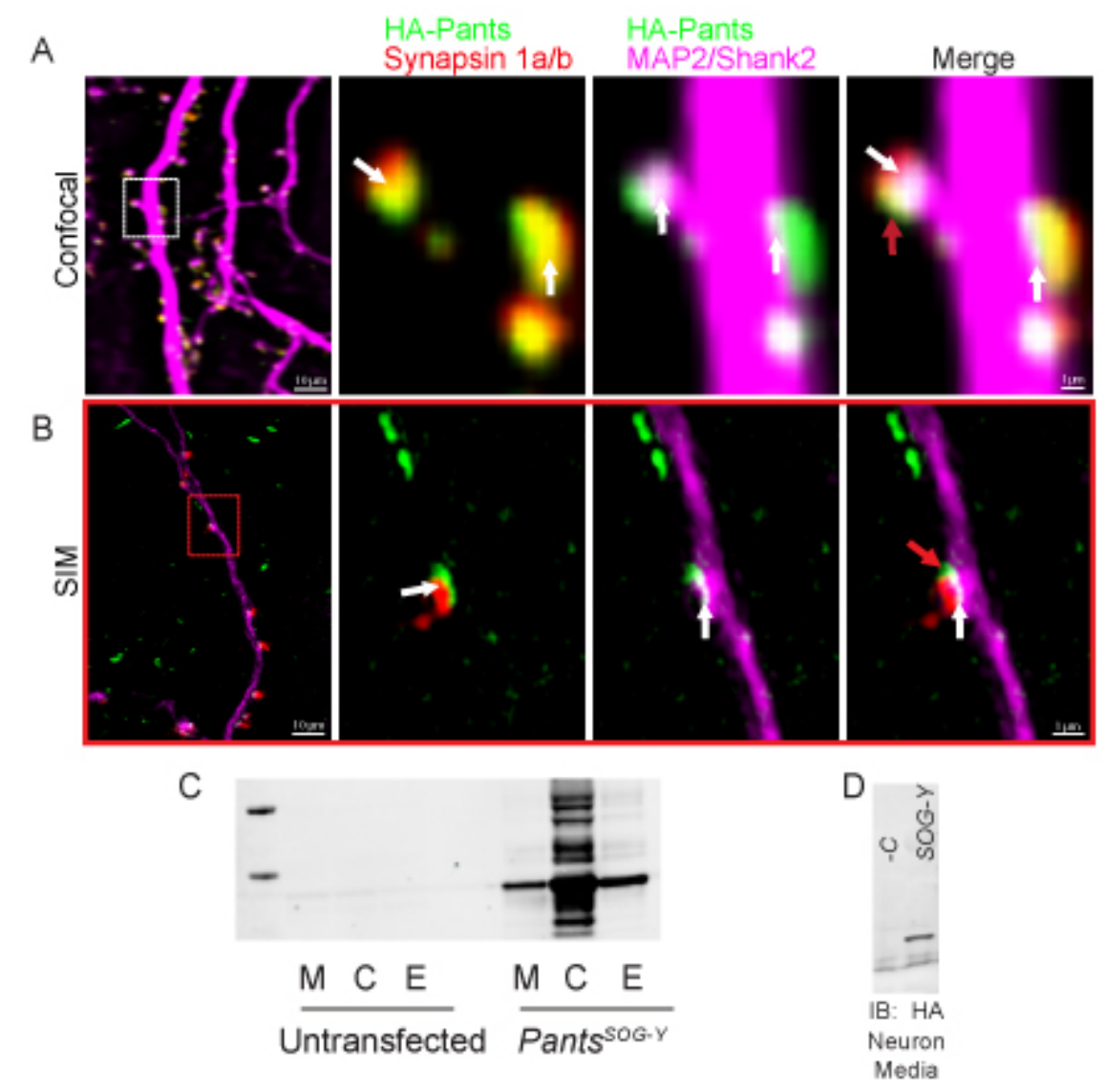

Fig. 2: Synaptic localization and release of Pants. A) Immunocytochemistry of 18-21 div primary neurons from Pants ${ }^{\text {SOG-Y }}$ hippocampus stained for HA, a Pre-synaptic marker (Synapsin 1a/b) and post-synaptic markers (MAP2 and Shank2) imaged with confocal microscopy. White arrows indicate areas of colocalization , and red arrows indicate suspected extra-synaptic pants that fails to co-localize with any markers. B) Structured Illumination Microscope imaging of the same staining from (A) to obtain better resolution. C) HA Western blot of HA IP from cellular lysates (C), extracellular matrix (E) fractions, and proteins precipitated from Neuro2a cell media (M) after transfection with a construct for over-expressing the Pants ${ }^{S O G-Y}$ fusion protein compared to untransfected controls. D) HA Western blot of HA IP of media collected from primary Pants ${ }^{\text {SOG-Y }}$ hippocampal neurons or Pants ${ }^{+/+}$negative control neurons. 
A

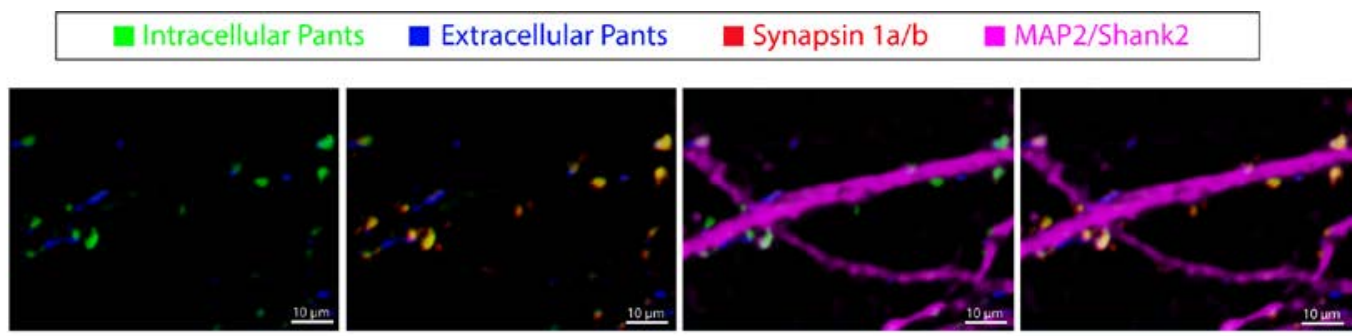

B
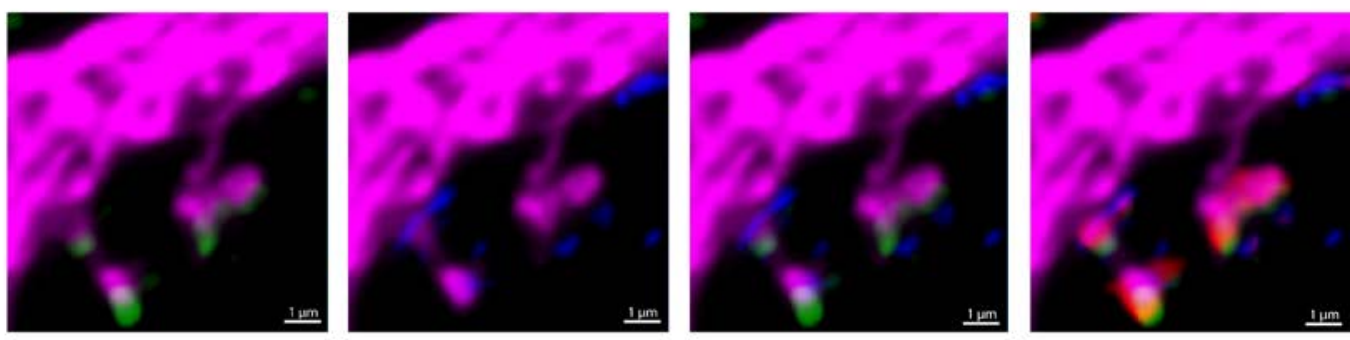

C
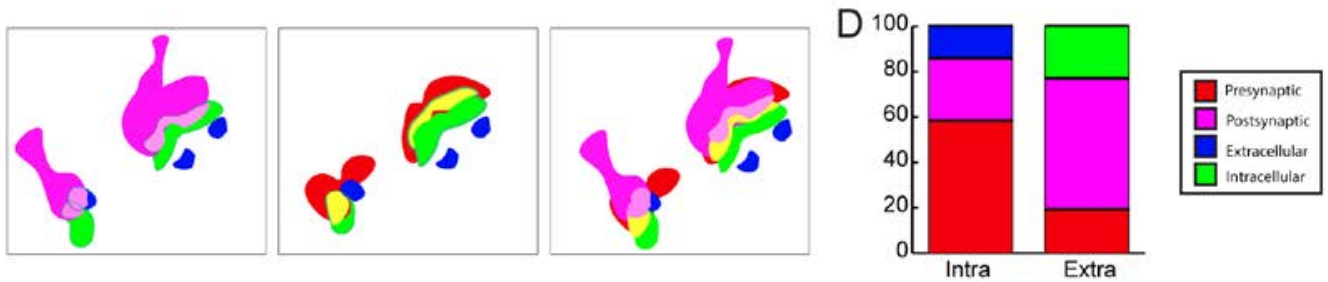

$\mathrm{E}$
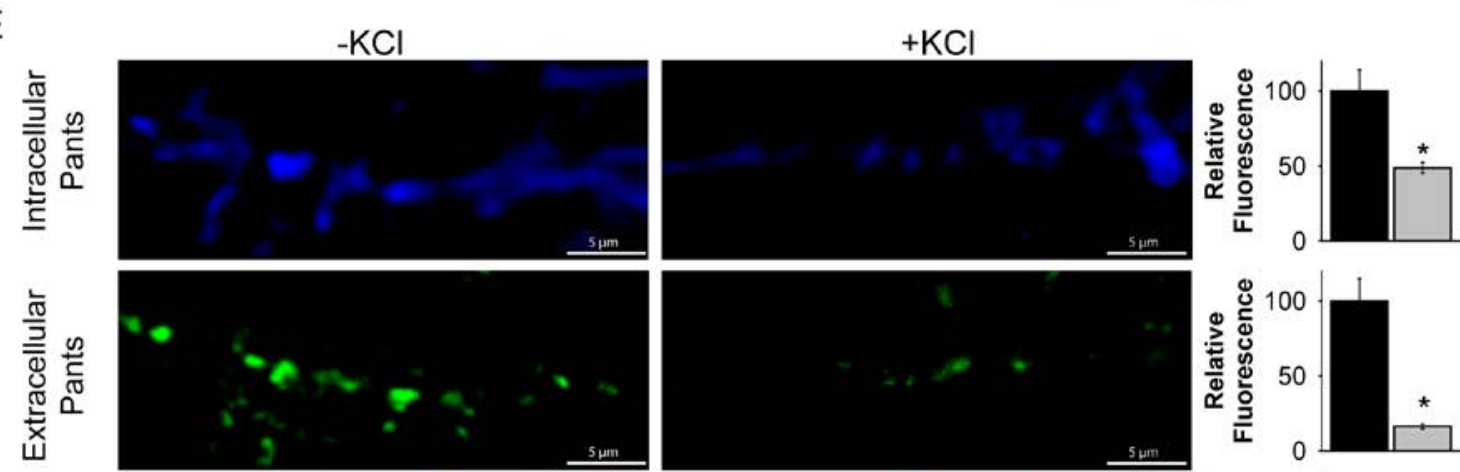

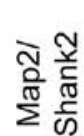
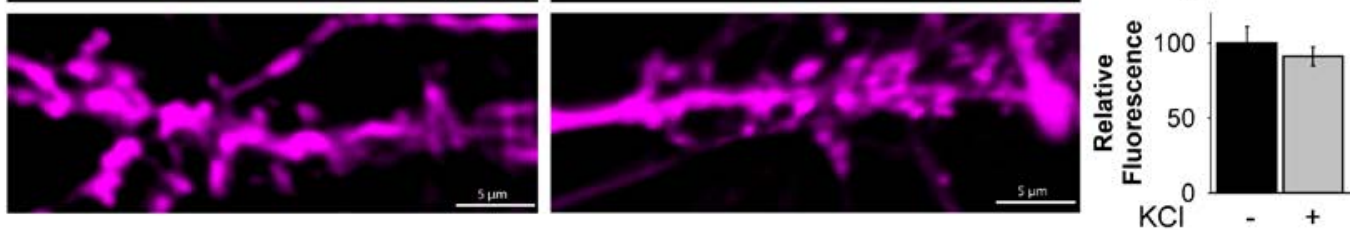

Fig. 3: Extrasynaptic Pants is downregulated in response to neuronal activity A)

Contrasting extracellular/intracellular immunocytochemistry staining for HA in cultured

hippocampal neurons. B-C) Co-localization of intra- and extra-cellular Pants with synaptic

markers D) Quantification of Pants co-localization with pre- and post-synaptic markers

correlation coefficients. E) Neuronal pre-synaptic and post synaptic HA-Pants staining with and 
bioRxiv preprint doi: https://doi.org/10.1101/2022.01.26.477857; this version posted January 28,2022 . The copyright holder for this preprint (which was not certified by peer review) is the author/funder, who has granted bioRxiv a license to display the preprint in perpetuity. It is made available under aCC-BY-NC-ND 4.0 International license.

without 10 seconds $60 \mathrm{mM} \mathrm{KCl}$ stimulation prior to fixation. Graphs at the right show quantification of fluorescence in dendritic ROIs, normalized to MAP2/Shank2 fluorescence. $n=3$

$\mathrm{P}<0.001$ (extracellular) and $\mathrm{P}=0.005$ (intracellular). 


\section{A}
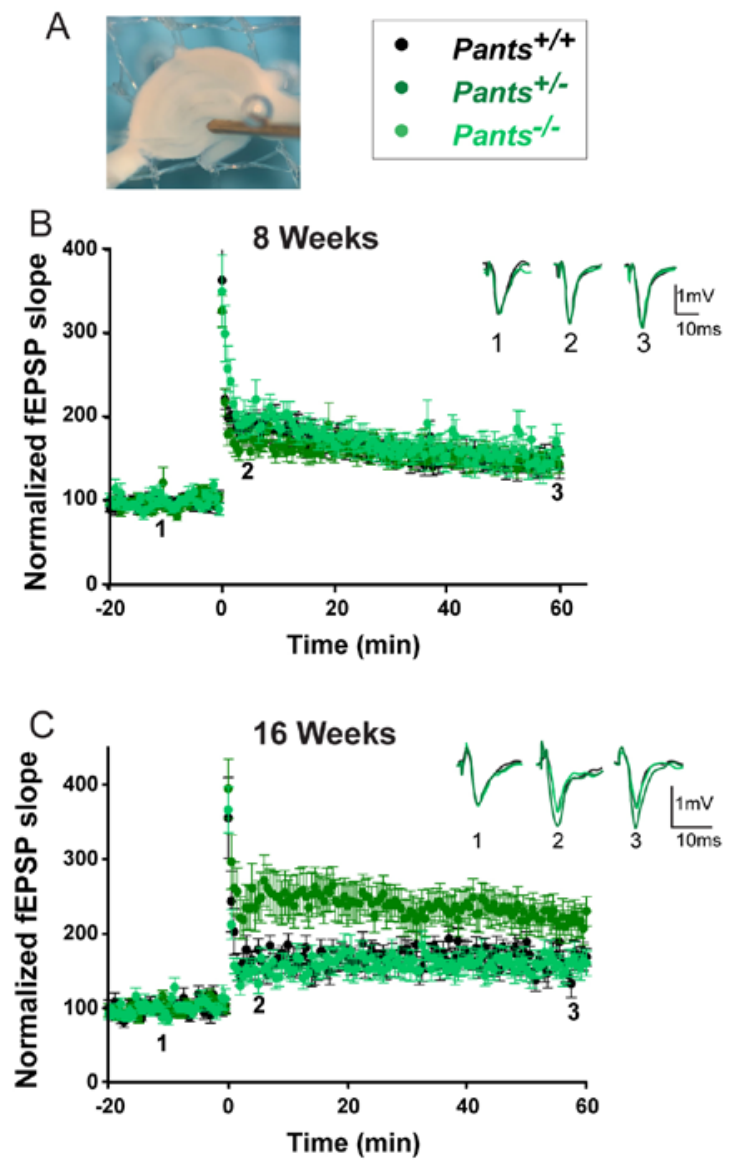

Fig. 4: Pants exerts an age-dependent, overdominant, negative effect on

hippocampal Mossy Fiber LTP. A) electrode placement for Mossy Fiber LTP measurement.

B-C) $100 \mathrm{~Hz}$ LTP recorded at MF synapses

from 8 week old (b), and 16 week old (c)

Pants $^{+/+}$(black), Pants ${ }^{+/-}$(dark green), and Pants $^{\text {-/ }}$ (light green) acute hippocampal slices. 8 week (n=6, 18 slices for Pants $^{+/+}, \mathrm{n}=10,30$ slices for Pants ${ }^{+-}$, and n=5, 15 slices for Pants ${ }^{-/-}$ . All $\mathrm{P}>0.503) .16$ week $(\mathrm{n}=4,18$ slices for Pants $^{+/+}, \mathrm{n}=5,18$ slices for Pants ${ }^{+/-}, \mathrm{n}=5,19$ slices for Pants ${ }^{-/} . \mathrm{P}<0.001$ for Pants $^{+/+}$vs.

Pants $^{+/} . \mathrm{P}=0.157$ for Pants $^{+/+}$vs. Pants ${ }^{-/} . \mathrm{P}<0.001$ for Pants $^{+/}$vs. Pants ${ }^{-/}$). 

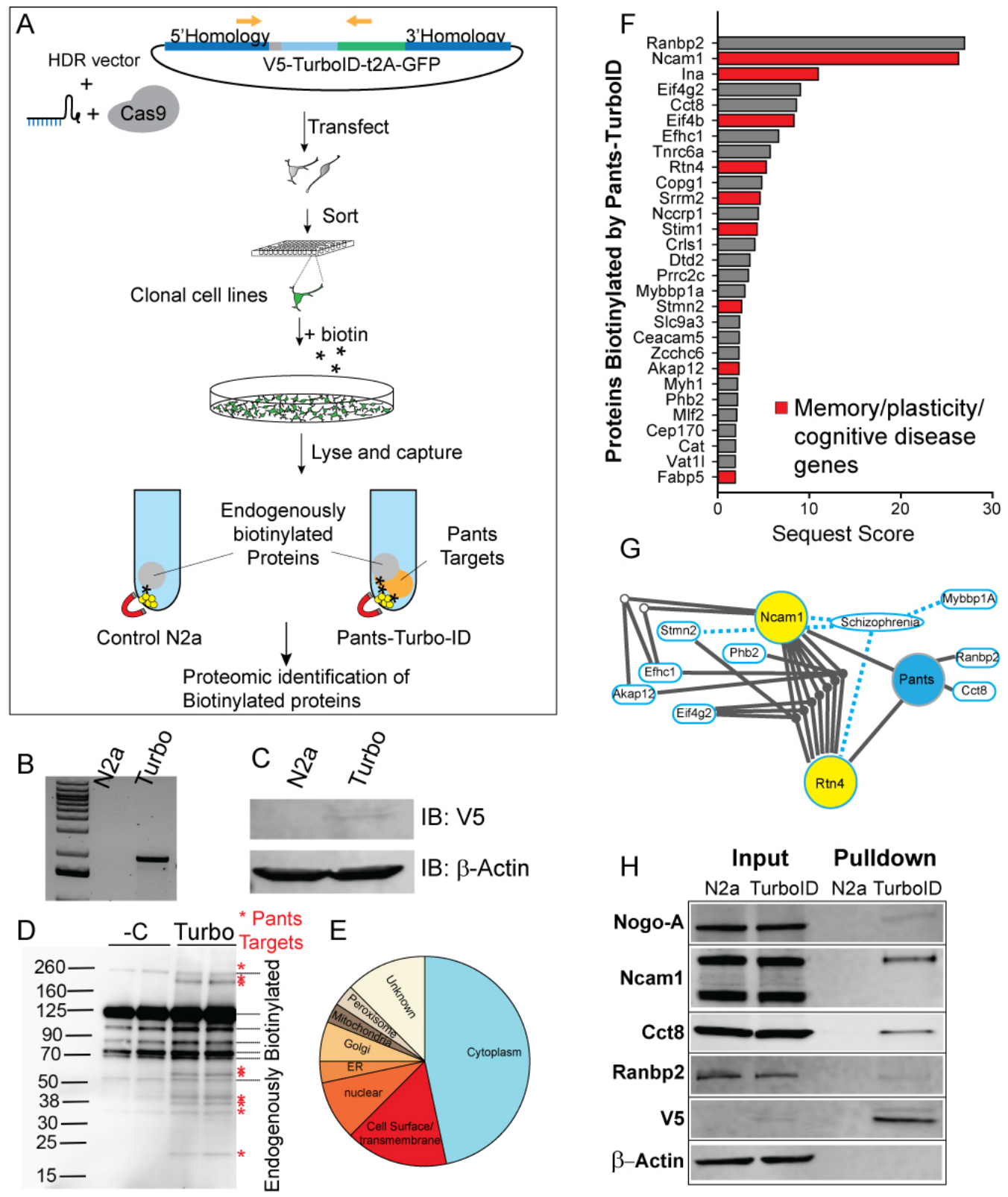

IB: Streptavidin-HRP

Fig. 5: Endogenous proximity labeling proteomics reveals the Pants interactome. A)

experimental design: a homomology-driven repair construct targeting the V5 epitope tag fused to the TurboID proximity labeling biotinylation enzyme followed by the self-cleaving t2A

peptide and GFP to the 3' end of the endogenous Pants locus was co-transfected with a vector carrying the sgRNA and Cas9 into Neuro2A cells. Single cells expressing GFP were then sorted into the wells of 96-well plates, generating clonal knock-in cell lines. B) Knock-in was verified 
by genotyping PCR of cell lines using a forward primer in the Pants gene and a reverse in GFP.

C) Expression of the Pants-V5-TurboID fusion protein in cell lines was verified by Western blotting of cell lysates with an antibody to the V5 epitope. D) Treatment of Pants-Turbo cells with $50 \mu \mathrm{M}$ biotin for 18 hours resulted in specific biotinylation of proteins not seen in N2A

controls, as verified by Streptavidin-HRP immunoblotting. E) Pie chart showing localization pattern of Pants targets identified by Proximity-labeling proteomics. F) Proteins uniquely biotinylated in Pants-TurboID cell line. G) IPA analysis of functional linkage between uniques proteomics hits, showing SZ connections and inter-gene connections. H) Biotinylation followed by streptavidin pulldown and Western blot with selected antibodies specific to Pants targets identified by Mass spectrometry to validate proteomics results. 

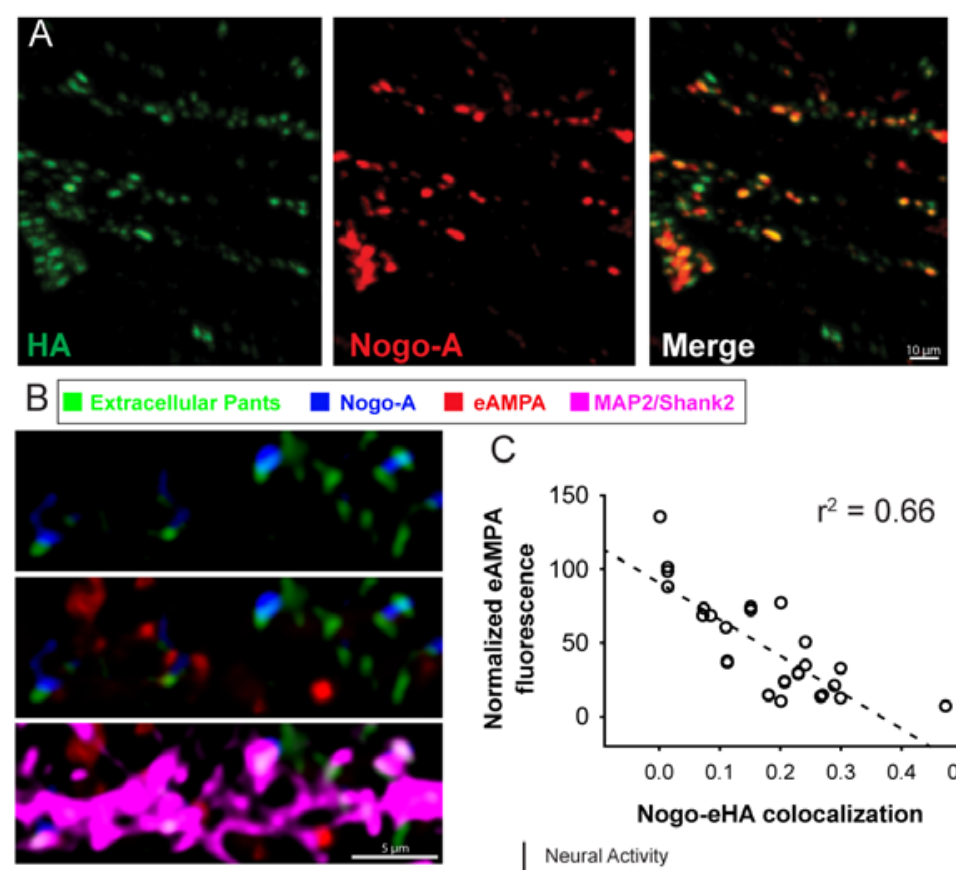

D
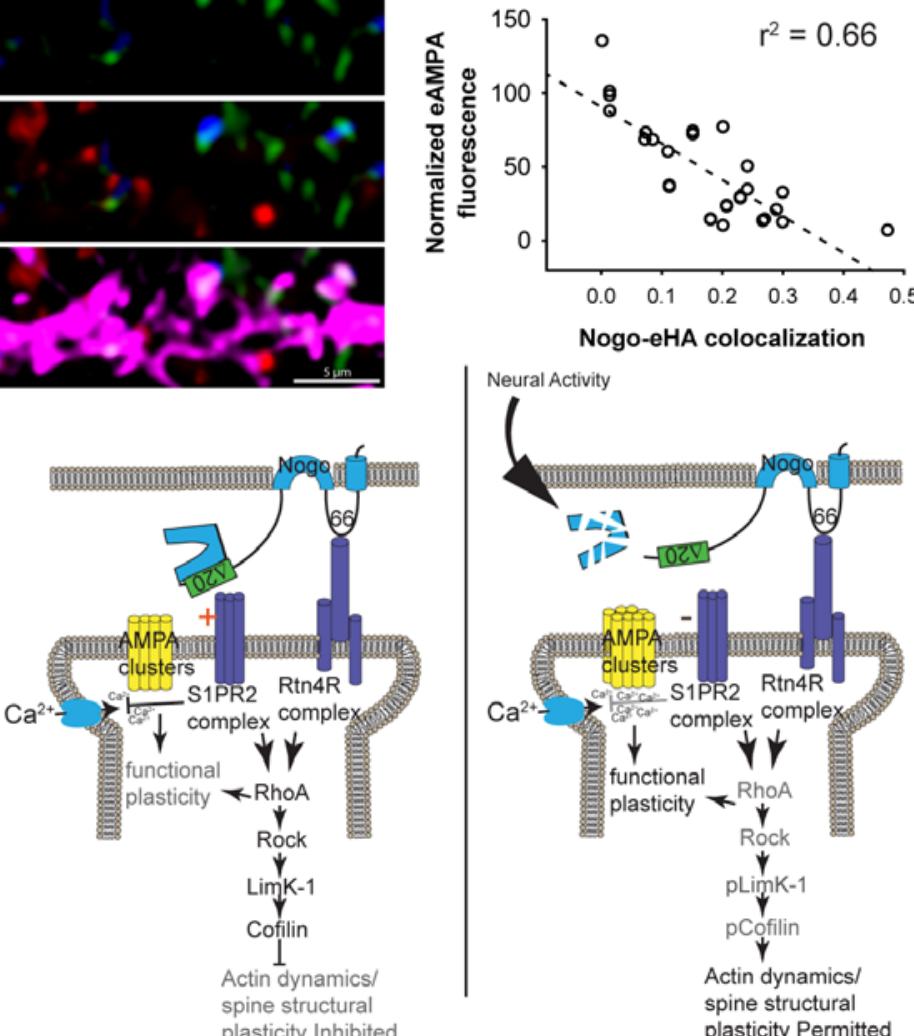

Nogo-eHA colocalization

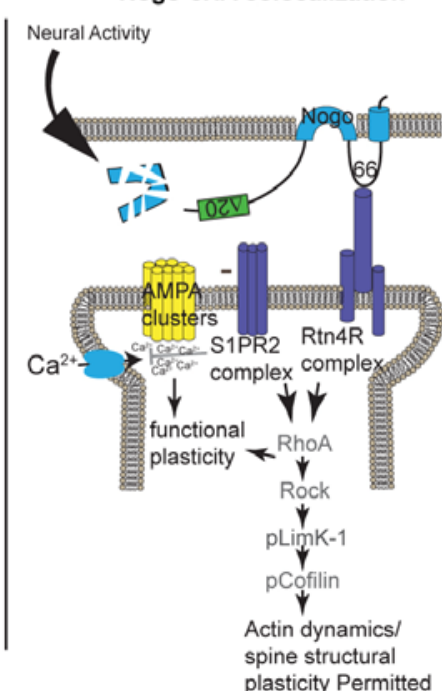

Fig. 6: Pants interacts with Rtn4/Nogo in vitro and in vivo. A) Immunocytochemical colocalization of Pants and Nogo-A in cultured Pants ${ }^{\text {SOG-Y }}$ hippocampal neurons B) AMPA receptor clustering at synapses where Pants is bound to Nogo-A versus Pants-free synapses after KCl stimulation. C) Correlation between Pants-Nogo-A co-localization and GluR1 AMPA receptor fluorescence in the membrane of spine ROIs after $\mathrm{KCl}$ stimulation. D) Model for the mechanism of Pants control of plasticity. Pants stabilizes the interaction of Nogo-A with receptors, inhibiting clustering of postsynaptic AMPA receptors at synaptic sites. Upon 
stimulation, Pants is degraded at synapses, reducing Nogo-A signaling and allowing AMPA receptor clustering at individual synapses.

\section{Acknowledgments:}

\section{Funding:}

A NARSAD Young Investigator Award from the Brain and Behavior Research Foundation. (LRE)

Louisiana Board of Regents RCS LEQSF(2018-21)RD-A-16 (LRE)

Tulane University Carol Lavin Bernick Faculty Grant (LRE)

Tulane Brain Institute Marko Spark Fund Award (LRE)

\section{Author contributions:}

Conceptualization: SK, LRE

Methodology: SK, ZC, AM, JG, LRE

Investigation: SK, ZC, AM, JG, LRE

Visualization: SK, LRE

Funding acquisition: LRE

Project administration: LRE

Supervision: SK, LRE

Writing - original draft: SK, LRE

Writing - review \& editing: SK, ZC, AM, JG, LRE

Competing interests: The authors declare that they have no competing interests. materials. 


\section{Supplementary Text}

Separating media from cell lysates and ECM fractions showed that overexpressed Pants is secreted from neuroblastoma cells, where it both interacts with ECM and is released into the media. To verify that these fractions had been correctly separated, we immunoblotted these

fractions with antibodies specific for the ECM marker Aggrecan, and observed signal only in the

\section{ECM fraction (fig. S1A).}

We further reasoned that Pants may be secreted from cells through large dense-core vesicles (LDCV), which is the route by which many neuropeptides are released. Using immunocytochemistry, we found modest colocalization with the LDCV-specific marker Chromagranin-B in Pants ${ }^{\text {SOG-Y }}$ transgenic neurons (fig. S1B). While inconclusive, this raises the possibility that micropeptides may be secreted from neurons using routes similar to those used by more traditionally studied neuropeptides that are cleaved from larger proteins.

We further confirmed extracellular localization of Pants in vivo, in hippocampal sections from Pants ${ }^{\text {SOG-Y/+ }}$ brain. In adult (16-week) sections, Pants staining occurs in a similar punctate pattern as in primary neurons. A portion of these puncta co-localize with WFA, a marker for ECM glycoproteins (fig. S2A). Treating sections with chABC, an ECM-dissolving enzyme, Pants signal in area CA3 is reduced by $41.5 \%$ (fig. S2B), further confirming that Pants is partially extracellular and associates with ECM proteins in the adult brain. 


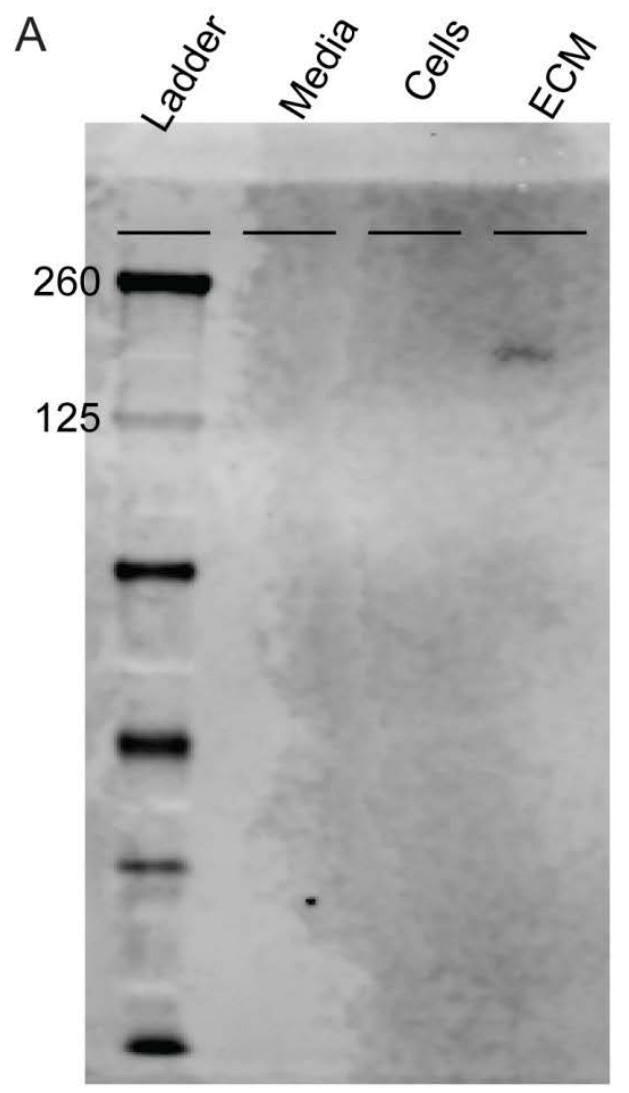

B
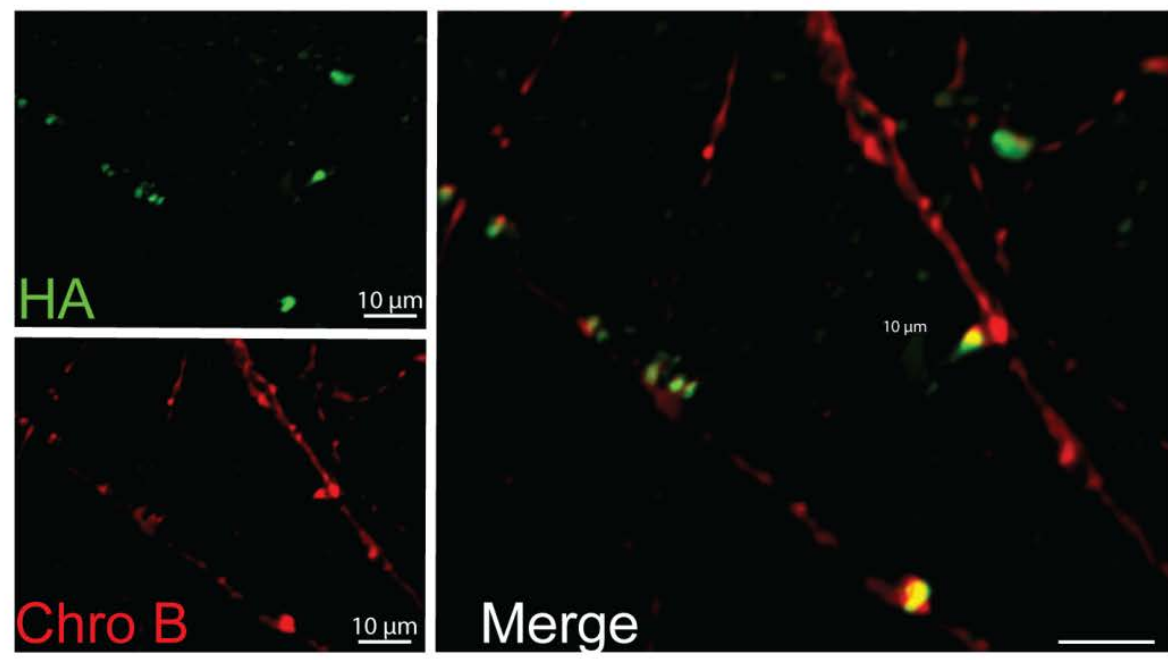

Immunoblot:Aggrecan

\section{Fig. S1. Validation of intracellular/extracellular (media)/extracellular(ECM) fractionation \\ protocol}

A) The ECM marker protein Aggrecan is found in the ECM fraction, but absent from cell lysate and media protein fractions. B) Immunocytochemistry of Pants ${ }^{\text {SOG-Y }}$ primary neurons co-stained with antibodies to HA and the LDCV marker chromogranin B. 

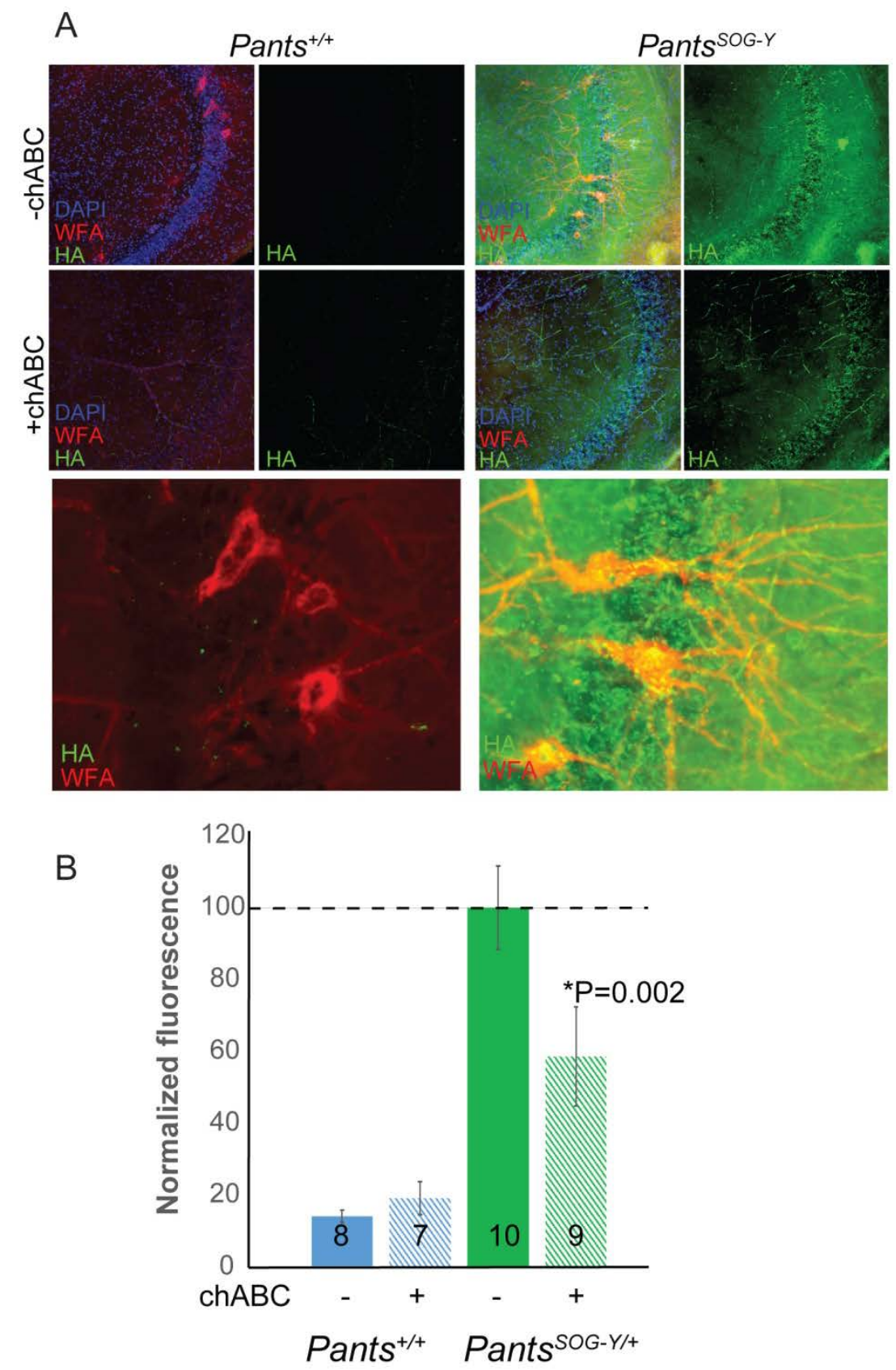

Fig. S2. Pants is extra-synaptic in the adult hippocampus. A) Immunohistochemical co-localization of HA with WFA, an ECM marker in 16 week hippocampal area CA3 in the absence and presence of chondroitinase ABC, and enzyme that digests ECM. B) Quantification of fluorescence intensity of HA staining in area CA3 in the absence and presence of chABC (n values: 3 mice each condition; number of slices on each bar). 

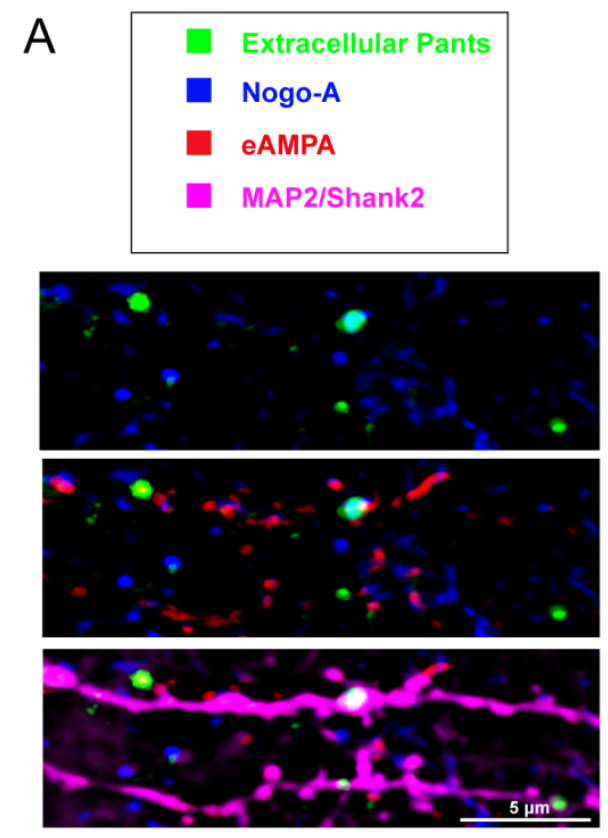

B

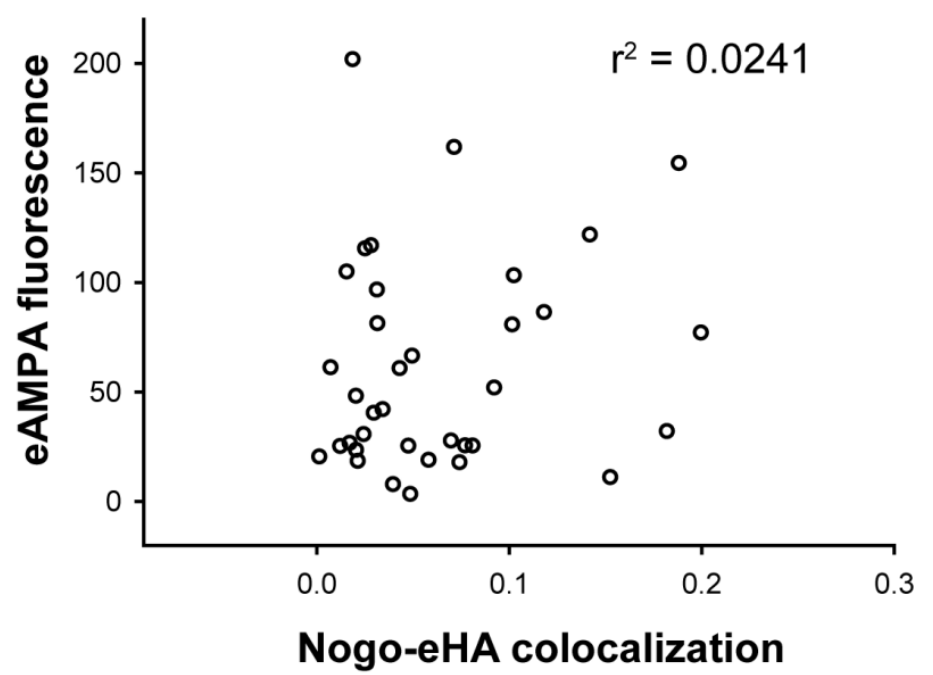

Fig. S3. No correlation between Pants-Nogo binding and AMPA receptor clustering at inactive synapses A) AMPA receptor clustering at synapses where Pants is bound to Nogo-A versus Pants-free synapses with no KCl stimulation. B) Correlation between Pants-Nogo-A co-localization and GluR1 AMPA receptor fluorescence in the membrane of spine ROIs with no KCl stimulation. 


\begin{tabular}{|c|c|c|c|c|}
\hline Antigen & Host & Manufacturer & Catolog\# & $\begin{array}{l}\text { Uses and } \\
\text { Dilutions }\end{array}$ \\
\hline Map2 & Chicken & Invitrogen & $\begin{array}{l}\text { PA1- } \\
10005\end{array}$ & ICC $1: 1,000$ \\
\hline Shank2 & $\begin{array}{l}\text { Guinea } \\
\text { Pig }\end{array}$ & SySy & 162204 & ICC 1:300 \\
\hline Synapsin 1a/b & Goat & Santa Cruz & sc-7379 & ICC 1:500 \\
\hline$\beta$-Actin & Mouse & Sigma-Aldrich & A5316 & WB $1: 10,000$ \\
\hline $\mathrm{HA}$ & Mouse & Santa Cruz & sc-7392 & ICC 1:300 \\
\hline $\mathrm{HA}$ & Rabbit & $\begin{array}{l}\text { Cell Signaling } \\
\text { Technologies }\end{array}$ & $3724 S$ & $\begin{array}{l}\text { WB 1:500 ICC } \\
1: 300\end{array}$ \\
\hline Rtn4/Nogo-A & Rabbit & Thermo Fisher Sci & PA520366 & $\begin{array}{l}\text { WB } 1: 1,000 \text { ICC } \\
1: 50\end{array}$ \\
\hline Ncam1 & Rabbit & Sigma-Aldrich & AB5032 & WB $1: 1,000$ \\
\hline ChgB & Rabbit & SySy & 259103 & ICC 1:200 \\
\hline Ranbp2 & Mouse & Santa Cruz & sc-74518 & WB 1:500 \\
\hline ССТ8 & Rabbit & Proteintech & $\begin{array}{l}\text { 12263-1- } \\
\text { AP }\end{array}$ & WB 1: 500 \\
\hline $\begin{array}{l}\text { Streptavidin- } \\
\text { HRP }\end{array}$ & $\mathrm{n} / \mathrm{a}$ & Invitrogen & S911 & WB $0.3 \mu \mathrm{g} / \mathrm{ml}$ \\
\hline WFA & $\mathrm{n} / \mathrm{a}$ & Vector Labs & B-1355-2 & ICC $1: 250$ \\
\hline GluR1 & Mouse & Thermo Fisher Sci & MA527694 & ICC 1:100 \\
\hline
\end{tabular}

Table S1.

Information about antibodies used in the study. 
Table S2. Unique proteins biotinylated in Pants-Turbo transgenic cell line

\begin{tabular}{|c|c|c|c|c|c|}
\hline Accession & Description & $\begin{array}{c}\text { Score } \\
\text { Sequest } \\
\text { HT }\end{array}$ & Gene Symbol & $\begin{array}{c}\text { Involved } \\
\text { in } \\
\text { Plasticity/ } \\
\text { memory }\end{array}$ & $\begin{array}{c}\text { Implicated } \\
\text { in } \\
\text { Cognitive } \\
\text { Disease }\end{array}$ \\
\hline Q9ERU9 & $\begin{array}{l}\text { E3 SUMO-protein ligase RanBP2 [OS=Mus } \\
\text { musculus] }\end{array}$ & 26.94 & Ranbp2 & & \\
\hline P13595 & $\begin{array}{l}\text { Neural cell adhesion molecule } 1 \text { [OS=Mus } \\
\text { musculus] }\end{array}$ & 26.29 & Ncam1 & $\begin{array}{l}\text { YES (50- } \\
53)\end{array}$ & \\
\hline P46660 & alpha-internexin [OS=Mus musculus] & 10.97 & Ina & & YES \\
\hline Q62448 & $\begin{array}{l}\text { Eukaryotic translation initiation factor } 4 \\
\text { gamma } 2 \text { [OS=Mus musculus] }\end{array}$ & 9.02 & Eif4g2 & & \\
\hline P42932 & $\begin{array}{l}\text { T-complex protein } 1 \text { subunit theta } \\
\text { [OS=Mus musculus] }\end{array}$ & 8.58 & Cct8 & & \\
\hline Q8BGD9 & $\begin{array}{l}\text { eukaryotic translation initiation factor 4B } \\
\text { [OS=Mus musculus] }\end{array}$ & 8.32 & Eif4b & & YES (54) \\
\hline Q9D9T8 & $\begin{array}{l}\text { EF-hand domain-containing protein } 1 \\
\text { [OS=Mus musculus] }\end{array}$ & 6.63 & Efhc1 & & \\
\hline Q3UHK8 & $\begin{array}{l}\text { Trinucleotide repeat-containing gene } 6 \mathrm{~A} \\
\text { protein [OS=Mus musculus] }\end{array}$ & 5.72 & Tnrc6a & & \\
\hline Q99P72-2 & Reticulon-4 [OS=Mus musculus] & 5.29 & Rtn4 & $\begin{array}{l}\text { YES (30, } \\
31)\end{array}$ & $\begin{array}{l}\text { YES (38, } \\
55-59)\end{array}$ \\
\hline Q9QZE5 & $\begin{array}{l}\text { Coatomer subunit gamma-1 [OS=Mus } \\
\text { musculus] }\end{array}$ & 4.79 & Copg; Copg1 & & \\
\hline Q8BTI8 & $\begin{array}{l}\text { serine/arginine repetitive matrix protein } 2 \\
\text { [OS=Mus musculus] }\end{array}$ & 4.6 & Srrm2 & & $\begin{array}{l}\text { YES (60, } \\
61)\end{array}$ \\
\hline $\mathrm{G} 3 \times 9 \mathrm{C} 2$ & F-box only protein 50 [OS=Mus musculus] & 4.42 & Nccrp1 & & \\
\hline P70302 & $\begin{array}{l}\text { stromal interaction molecule } 1 \text { [OS=Mus } \\
\text { musculus] }\end{array}$ & 4.3 & Stim1 & $\begin{array}{l}\text { YES }(62- \\
64)\end{array}$ & \\
\hline Q80ZM8 & $\begin{array}{l}\text { Cardiolipin synthase (CMP-forming) } \\
\text { [OS=Mus musculus] }\end{array}$ & 4.04 & Crls1 & & \\
\hline $\begin{array}{l}\text { Q8BHA3- } \\
2\end{array}$ & $\begin{array}{l}\text { Isoform } 2 \text { of Putative D-tyrosyl-tRNA(Tyr) } \\
\text { deacylase } 2 \text { [OS=Mus musculus] }\end{array}$ & 3.49 & $\begin{array}{l}\text { 6530401N04Rik; } \\
\text { Dtd2 }\end{array}$ & & \\
\hline Q3TLH4 & Protein Prrc2c [OS=Mus musculus] & 3.34 & Prrc2c & & \\
\hline Q7TPV4 & $\begin{array}{l}\text { Myb-binding protein } 1 \mathrm{~A}[\mathrm{OS}=\mathrm{Mus} \\
\text { musculus] }\end{array}$ & 2.95 & Mybbp1a & & \\
\hline P55821 & Stathmin-2 [OS=Mus musculus] & 2.61 & Stmn2 & $\begin{array}{l}\text { YES (65- } \\
67)\end{array}$ & $\begin{array}{l}\text { YES }(68, \\
69)\end{array}$ \\
\hline G3X939 & $\begin{array}{l}\text { sodium/hydrogen exchanger } 3 \text { [OS=Mus } \\
\text { musculus] }\end{array}$ & 2.36 & Slc9a3 & & \\
\hline Q3UKK2 & $\begin{array}{l}\text { Carcinoembryonic antigen-related cell } \\
\text { adhesion molecule } 5 \text { [OS=Mus musculus] }\end{array}$ & 2.34 & Ceacam5 & & \\
\hline $\begin{array}{l}\text { Q9WTQ5- } \\
1\end{array}$ & $\begin{array}{l}\text { A-kinase anchor protein } 12 \text { [OS=Mus } \\
\text { musculus] }\end{array}$ & 2.32 & Akap12 & $\begin{array}{l}\text { YES }(70, \\
71)\end{array}$ & \\
\hline Q5BLK4 & $\begin{array}{l}\text { terminal uridylyltransferase } 7 \text { [OS=Mus } \\
\text { musculus] }\end{array}$ & 2.32 & Zcchc6 & & \\
\hline 035129 & Prohibitin-2 [OS=Mus musculus] & 2.16 & Phb2 & & \\
\hline
\end{tabular}




\begin{tabular}{|l|l|r|l|l|l|} 
Q99KX1 & $\begin{array}{l}\text { Myeloid leukemia factor 2 [OS=Mus } \\
\text { musculus] }\end{array}$ & 2.08 & Mlf2 & & \\
\hline Q6A065 & $\begin{array}{l}\text { Centrosomal protein of 170 kDa [OS=Mus } \\
\text { musculus] }\end{array}$ & 1.95 & Cep170 & & \\
\hline P24270 & catalase [OS=Mus musculus] & 1.94 & Cat & & \\
\hline Q80TB8 & $\begin{array}{l}\text { Synaptic vesicle membrane protein VAT-1 } \\
\text { homolog-like [OS=Mus musculus] }\end{array}$ & 1.92 & Vat1l & & \\
\hline Q05816 & $\begin{array}{l}\text { Fatty acid-binding protein, epidermal } \\
\text { [OS=Mus musculus] }\end{array}$ & 1.9 & Fabp5 & & $\begin{array}{l}\text { YES (72, } \\
73)\end{array}$ \\
\hline
\end{tabular}

\section{Data Supp_Table_S3}

Raw proteins identified in streptavidin pulldown from N2a negative control

\section{Data Supp_Table_S4}

10 Raw proteins identified in streptavidin pulldown from Pants-TurboID transgenic cell line. Contaminant value of False indicates that the protein is unique to the transgenic samples. 


\section{References}

1. K. Labun et al., CHOPCHOP v3: expanding the CRISPR web toolbox beyond genome editing. Nucleic Acids Res 47, W171-W174 (2019).

2. $\quad$ K. F. Cho et al., Proximity labeling in mammalian cells with TurboID and split-TurboID. Nat Protoc 15, 3971-3999 (2020).

3. T. C. Branon et al., Efficient proximity labeling in living cells and organisms with TurboID. Nat Biotechnol 36, 880-887 (2018).

4. J. C. Harman, J. J. Guidry, J. M. Gidday, Comprehensive characterization of the adult ND4 Swiss Webster mouse retina: Using discovery-based mass spectrometry to decipher the total proteome and phosphoproteome. Mol Vis 24, 875-889 (2018).

5. $\quad$ N. L. Carrodus, K. S. Teng, K. M. Munro, M. J. Kennedy, J. M. Gunnersen, Differential labeling of cellsurface and internalized proteins after antibody feeding of live cultured neurons. J Vis Exp, e51139 (2014).

6. L. R. Earls et al., Age-dependent microRNA control of synaptic plasticity in 22q11 deletion syndrome and schizophrenia. J Neurosci 32, 14132-14144 (2012).

7. S. E. Lauri et al., A critical role of a facilitatory presynaptic kainate receptor in mossy fiber LTP. Neuron 32, 697-709 (2001).

8. A. L. Hellewell, S. Rosini, J. C. Adams, A Rapid, Scalable Method for the Isolation, Functional Study, and Analysis of Cell-derived Extracellular Matrix. J Vis Exp, (2017).

9. S. Arami, M. Jucker, M. Schachner, H. Welzl, The effect of continuous intraventricular infusion of L1 and NCAM antibodies on spatial learning in rats. Behav Brain Res 81, 81-87 (1996).

10. A. Luthi, J. P. Laurent, A. Figurov, D. Muller, M. Schachner, Hippocampal long-term potentiation and neural cell adhesion molecules L1 and NCAM. Nature 372, 777-779 (1994).

11. L. C. Ronn, E. Bock, D. Linnemann, H. Jahnsen, NCAM-antibodies modulate induction of long-term potentiation in rat hippocampal CA1. Brain Res 677, 145-151 (1995).

12. R. Bisaz, P. Boadas-Vaello, D. Genoux, C. Sandi, Age-related cognitive impairments in mice with a conditional ablation of the neural cell adhesion molecule. Learn Mem 20, 183-193 (2013).

13. B. Bettegazzi et al., Casein Kinase 2 dependent phosphorylation of eIF4B regulates BACE1 expression in Alzheimer's disease. Cell Death Dis 12, 769 (2021).

14. A. Delekate, M. Zagrebelsky, S. Kramer, M. E. Schwab, M. Korte, NogoA restricts synaptic plasticity in the adult hippocampus on a fast time scale. Proc Natl Acad Sci U S A 108, 2569-2574 (2011).

15. B. Tews et al., Synthetic microRNA-mediated downregulation of Nogo-A in transgenic rats reveals its role as regulator of synaptic plasticity and cognitive function. Proc Natl Acad Sci U S A 110, 6583-6588 (2013).

16. V. Gil et al., Nogo-A expression in the human hippocampus in normal aging and in Alzheimer disease. $J$ Neuropathol Exp Neurol 65, 433-444 (2006).

17. Y. B. Hu et al., ROCK1 Is Associated with Alzheimer's Disease-Specific Plaques, as well as Enhances Autophagosome Formation But not Autophagic Abeta Clearance. Front Cell Neurosci 10, 253 (2016).

18. J. H. Park et al., Alzheimer precursor protein interaction with the Nogo-66 receptor reduces amyloid-beta plaque deposition. J Neurosci 26, 1386-1395 (2006).

19. J. H. Park, S. M. Strittmatter, Nogo receptor interacts with brain APP and Abeta to reduce pathologic changes in Alzheimer's transgenic mice. Curr Alzheimer Res 4, 568-570 (2007).

20. J. H. Park et al., Subcutaneous Nogo receptor removes brain amyloid-beta and improves spatial memory in Alzheimer's transgenic mice. J Neurosci 26, 13279-13286 (2006).

21. G. Wang et al., MicroRNA-146a suppresses ROCK1 allowing hyperphosphorylation of tau in Alzheimer's disease. Sci Rep 6, 26697 (2016).

22. P. J. McMillan et al., Pathological tau drives ectopic nuclear speckle scaffold protein SRRM2 accumulation in neuron cytoplasm in Alzheimer's disease. Acta Neuropathol Commun 9, 117 (2021).

23. H. Tanaka et al., The intellectual disability gene PQBP1 rescues Alzheimer's disease pathology. Mol

Psychiatry 23, 2090-2110 (2018).

24. G. Garcia-Alvarez et al., Impaired spatial memory and enhanced long-term potentiation in mice with forebrain-specific ablation of the Stim genes. Front Behav Neurosci 9, 180 (2015).

25. T. Kyung et al., Optogenetic control of endogenous Ca(2+) channels in vivo. Nat Biotechnol 33, $1092-1096$ (2015).

26. L. Majewski et al., Overexpression of STIM1 in neurons in mouse brain improves contextual learning and impairs long-term depression. Biochim Biophys Acta Mol Cell Res 1864, 1071-1087 (2017). 
27. H. Morii, T. Yamada, I. Nakano, J. M. Coulson, N. Mori, Site-specific phosphorylation of SCG10 in neuronal plasticity: role of Ser73 phosphorylation by N-methyl D-aspartic acid receptor activation in rat hippocampus. Neurosci Lett 396, 241-246 (2006).

28. H. Peng, B. E. Derrick, J. L. Martinez, Jr., Identification of upregulated SCG10 mRNA expression Neurosci 23, 6617-6626 (2003).

29. G. P. Shumyatsky et al., stathmin, a gene enriched in the amygdala, controls both learned and innate fear. Cell 123, 697-709 (2005).

30. T. Okazaki et al., SCG10, a neuron-specific growth-associated protein in Alzheimer's disease. Neurobiol Aging 16, 883-894 (1995).

31. J. Wang et al., SCG10 promotes non-amyloidogenic processing of amyloid precursor protein by facilitating its trafficking to the cell surface. Hum Mol Genet 22, 4888-4900 (2013).

32. R. Havekes et al., Gravin orchestrates protein kinase A and beta2-adrenergic receptor signaling critical for synaptic plasticity and memory. J Neurosci 32, 18137-18149 (2012).

33. T. Maki et al., A-Kinase Anchor Protein 12 Is Required for Oligodendrocyte Differentiation in Adult White Matter. Stem Cells 36, 751-760 (2018).

34. C. Shimamoto et al., Functional characterization of FABP3, 5 and 7 gene variants identified in schizophrenia and autism spectrum disorder and mouse behavioral studies. Hum Mol Genet 23, 6495-6511 (2014).

35. S. Yu, L. Levi, G. Casadesus, G. Kunos, N. Noy, Fatty acid-binding protein 5 (FABP5) regulates cognitive function both by decreasing anandamide levels and by activating the nuclear receptor peroxisome proliferator-activated receptor beta/delta (PPARbeta/delta) in the brain. J Biol Chem 289, 12748-12758 (2014). 


\section{References}

1. M. Schneider et al., Psychiatric disorders from childhood to adulthood in 22q11.2 deletion syndrome: results from the International Consortium on Brain and Behavior in 22q11.2 Deletion Syndrome. Am J Psychiatry 171, 627-639 (2014).

2. S. Chun et al., Thalamic miR-338-3p mediates auditory thalamocortical disruption and its late onset in models of 22q11.2 microdeletion. Nat Med 23, 39-48 (2017).

3. S. Chun et al., Specific disruption of thalamic inputs to the auditory cortex in schizophrenia models. Science 344, 1178-1182 (2014).

4. P. Devaraju et al., Haploinsufficiency of the 22q11.2 microdeletion gene Mrpl40 disrupts short-term synaptic plasticity and working memory through dysregulation of mitochondrial calcium. Mol Psychiatry, (2016).

5. L. R. Earls et al., Dysregulation of presynaptic calcium and synaptic plasticity in a mouse model of 22q11 deletion syndrome. J Neurosci 30, 15843-15855 (2010).

6. L. R. Earls et al., Age-dependent microRNA control of synaptic plasticity in 22q11 deletion syndrome and schizophrenia. J Neurosci 32, 14132-14144 (2012).

7. $\quad$ N. T. Ingolia et al., Ribosome profiling reveals pervasive translation outside of annotated protein-coding genes. Cell Rep 8, 1365-1379 (2014).

8. D. M. Anderson et al., A micropeptide encoded by a putative long noncoding RNA regulates muscle performance. Cell 160, 595-606 (2015).

9. M. I. Galindo, J. I. Pueyo, S. Fouix, S. A. Bishop, J. P. Couso, Peptides encoded by short ORFs control development and define a new eukaryotic gene family. PLoS Biol 5, e106 (2007).

10. T. Kondo et al., Small peptide regulators of actin-based cell morphogenesis encoded by a polycistronic mRNA. Nat Cell Biol 9, 660-665 (2007).

11. A. A. Bazzini et al., Identification of small ORFs in vertebrates using ribosome footprinting and evolutionary conservation. EMBO J 33, 981-993 (2014).

12. J. Crappe et al., Combining in silico prediction and ribosome profiling in a genome-wide search for novel putatively coding sORFs. BMC Genomics 14, 648 (2013).

13. S. D. Mackowiak et al., Extensive identification and analysis of conserved small ORFs in animals. Genome

14. V. Olexiouk et al., sORFs.org: a repository of small ORFs identified by ribosome profiling. Nucleic Acids Res 44, D324-329 (2016).

15. C. A. Makarewich, S. Bezprozvannaya, A. M. Gibson, R. Bassel-Duby, E. N. Olson, Gene Therapy With the DWORF Micropeptide Attenuates Cardiomyopathy in Mice. Circ Res 127, 1340-1342 (2020).

16. L. Niu et al., A micropeptide encoded by lncRNA MIR155HG suppresses autoimmune inflammation via modulating antigen presentation. Sci Adv 6, eaaz2059 (2020).

17. S. A. M. Ebrahim, G. J. S. Talross, J. R. Carlson, Sight of parasitoid wasps accelerates sexual behavior and upregulates a micropeptide gene in Drosophila. Nat Commun 12, 2453 (2021).

18. P. H. Sudmant, H. Lee, D. Dominguez, M. Heiman, C. B. Burge, Widespread Accumulation of RibosomeAssociated Isolated 3' UTRs in Neuronal Cell Populations of the Aging Brain. Cell Rep 25, 2447-2456 e2444 (2018).

19. S. Kragness, M. A. A. Harrison, J. J. Westmoreland, A. Burstain, L. R. Earls, Age-dependent expression pattern in the mammalian brain of a novel, small peptide encoded in the 22q11.2 deletion syndrome region. Gene Expr Patterns 28, 95-103 (2018).

$20 . \quad$ C. A. Makarewich, E. N. Olson, Mining for Micropeptides. Trends Cell Biol 27, 685-696 (2017).

21. J. D. Bendtsen, L. J. Jensen, N. Blom, G. Von Heijne, S. Brunak, Feature-based prediction of non-classical and leaderless protein secretion. Protein Eng Des Sel 17, 349-356 (2004).

22. N. L. Carrodus, K. S. Teng, K. M. Munro, M. J. Kennedy, J. M. Gunnersen, Differential labeling of cellsurface and internalized proteins after antibody feeding of live cultured neurons. $J$ Vis Exp, e51139 (2014). 36, 880-887 (2018).

24. E. Persohn, G. E. Pollerberg, M. Schachner, Immunoelectron-microscopic localization of the $180 \mathrm{kD}$ component of the neural cell adhesion molecule N-CAM in postsynaptic membranes. J Comp Neurol 288, 92-100 (1989).

$55 \quad 25 . \quad$ T. Schuster, M. Krug, H. Hassan, M. Schachner, Increase in proportion of hippocampal spine synapses expressing neural cell adhesion molecule NCAM180 following long-term potentiation. J Neurobiol 37, 359-372 (1998). 
26. D. Muller et al., PSA-NCAM is required for activity-induced synaptic plasticity. Neuron 17, 413-422 (1996).

27. C. M. Lewis et al., Genome scan meta-analysis of schizophrenia and bipolar disorder, part II: Schizophrenia. Am J Hum Genet 73, 34-48 (2003).

28. C. R. Marshall et al., Contribution of copy number variants to schizophrenia from a genome-wide study of 41,321 subjects. Nat Genet 49, 27-35 (2017).

29. M. E. Schwab, Nogo and axon regeneration. Curr Opin Neurobiol 14, 118-124 (2004).

30. A. Delekate, M. Zagrebelsky, S. Kramer, M. E. Schwab, M. Korte, NogoA restricts synaptic plasticity in the adult hippocampus on a fast time scale. Proc Natl Acad Sci U S A 108, 2569-2574 (2011).

31. B. Tews et al., Synthetic microRNA-mediated downregulation of Nogo-A in transgenic rats reveals its role as regulator of synaptic plasticity and cognitive function. Proc Natl Acad Sci U S A 110, 6583-6588 (2013).

32. A. E. Fournier, T. GrandPre, S. M. Strittmatter, Identification of a receptor mediating Nogo-66 inhibition of axonal regeneration. Nature 409, 341-346 (2001).

33. A. Kempf et al., The sphingolipid receptor S1PR2 is a receptor for Nogo-a repressing synaptic plasticity.

34. S. Fricke et al., Fast Regulation of GABAAR Diffusion Dynamics by Nogo-A Signaling. Cell Rep 29, 671684 e676 (2019).

35. S. Jitsuki et al., Nogo Receptor Signaling Restricts Adult Neural Plasticity by Limiting Synaptic AMPA Receptor Delivery. Cereb Cortex 26, 427-439 (2016). dynamics. Hippocampus 26, 816-831 (2016).

37. E. D. Gundelfinger, R. Frischknecht, D. Choquet, M. Heine, Converting juvenile into adult plasticity: a role for the brain's extracellular matrix. Eur J Neurosci 31, 2156-2165 (2010).

38. V. Gil et al., Nogo-A expression in the human hippocampus in normal aging and in Alzheimer disease. $J$ Neuropathol Exp Neurol 65, 433-444 (2006).

39. H. D. VanGuilder Starkey, G. V. Bixler, W. E. Sonntag, W. M. Freeman, Expression of NgR1antagonizing proteins decreases with aging and cognitive decline in rat hippocampus. Cell Mol Neurobiol 33, 483-488 (2013).

40. H. D. VanGuilder Starkey, W. E. Sonntag, W. M. Freeman, Increased hippocampal NgR1 signaling machinery in aged rats with deficits of spatial cognition. Eur J Neurosci 37, 1643-1658 (2013).

Alzheimer's Disease. Neuroscientist 27, 487-505 (2021).

42. L. Yang et al., Transcriptomic Landscape of von Economo Neurons in Human Anterior Cingulate Cortex Revealed by Microdissected-Cell RNA Sequencing. Cereb Cortex 29, 838-851 (2019).

43. J. M. Allman et al., The von Economo neurons in frontoinsular and anterior cingulate cortex in great apes and humans. Brain Struct Funct 214, 495-517 (2010).

44. M. Brune et al., Von Economo neuron density in the anterior cingulate cortex is reduced in early onset schizophrenia. Acta Neuropathol 119, 771-778 (2010).

45. K. Labun et al., CHOPCHOP v3: expanding the CRISPR web toolbox beyond genome editing. Nucleic Acids Res 47, W171-W174 (2019).

46. K. F. Cho et al., Proximity labeling in mammalian cells with TurboID and split-TurboID. Nat Protoc 15, 3971-3999 (2020).

47. J. C. Harman, J. J. Guidry, J. M. Gidday, Comprehensive characterization of the adult ND4 Swiss Webster mouse retina: Using discovery-based mass spectrometry to decipher the total proteome and phosphoproteome. Mol Vis 24, 875-889 (2018).

48. S. E. Lauri et al., A critical role of a facilitatory presynaptic kainate receptor in mossy fiber LTP. Neuron 32, 697-709 (2001).

49. A. L. Hellewell, S. Rosini, J. C. Adams, A Rapid, Scalable Method for the Isolation, Functional Study, and Analysis of Cell-derived Extracellular Matrix. J Vis Exp, (2017).

50. S. Arami, M. Jucker, M. Schachner, H. Welzl, The effect of continuous intraventricular infusion of L1 and NCAM antibodies on spatial learning in rats. Behav Brain Res 81, 81-87 (1996).

51. A. Luthi, J. P. Laurent, A. Figurov, D. Muller, M. Schachner, Hippocampal long-term potentiation and neural cell adhesion molecules L1 and NCAM. Nature 372, 777-779 (1994).

52. L. C. Ronn, E. Bock, D. Linnemann, H. Jahnsen, NCAM-antibodies modulate induction of long-term potentiation in rat hippocampal CA1. Brain Res 677, 145-151 (1995).

53. R. Bisaz, P. Boadas-Vaello, D. Genoux, C. Sandi, Age-related cognitive impairments in mice with a conditional ablation of the neural cell adhesion molecule. Learn Mem 20, 183-193 (2013). 
54. B. Bettegazzi et al., Casein Kinase 2 dependent phosphorylation of eIF4B regulates BACE1 expression in Alzheimer's disease. Cell Death Dis 12, 769 (2021).

55. Y. B. Hu et al., ROCK1 Is Associated with Alzheimer's Disease-Specific Plaques, as well as Enhances Autophagosome Formation But not Autophagic Abeta Clearance. Front Cell Neurosci 10, 253 (2016).

56. J. H. Park et al., Alzheimer precursor protein interaction with the Nogo-66 receptor reduces amyloid-beta plaque deposition. J Neurosci 26, 1386-1395 (2006).

57. J. H. Park, S. M. Strittmatter, Nogo receptor interacts with brain APP and Abeta to reduce pathologic changes in Alzheimer's transgenic mice. Curr Alzheimer Res 4, 568-570 (2007).

58. J. H. Park et al., Subcutaneous Nogo receptor removes brain amyloid-beta and improves spatial memory in Alzheimer's transgenic mice. J Neurosci 26, 13279-13286 (2006).

59. G. Wang et al., MicroRNA-146a suppresses ROCK1 allowing hyperphosphorylation of tau in Alzheimer's disease. Sci Rep 6, 26697 (2016).

60. P. J. McMillan et al., Pathological tau drives ectopic nuclear speckle scaffold protein SRRM2 accumulation in neuron cytoplasm in Alzheimer's disease. Acta Neuropathol Commun 9, 117 (2021).

61. H. Tanaka et al., The intellectual disability gene PQBP1 rescues Alzheimer's disease pathology. Mol Psychiatry 23, 2090-2110 (2018).

62. G. Garcia-Alvarez et al., Impaired spatial memory and enhanced long-term potentiation in mice with forebrain-specific ablation of the Stim genes. Front Behav Neurosci 9, 180 (2015).

63. T. Kyung et al., Optogenetic control of endogenous Ca(2+) channels in vivo. Nat Biotechnol 33, $1092-1096$ (2015).

64. L. Majewski et al., Overexpression of STIM1 in neurons in mouse brain improves contextual learning and impairs long-term depression. Biochim Biophys Acta Mol Cell Res 1864, 1071-1087 (2017).

65. H. Morii, T. Yamada, I. Nakano, J. M. Coulson, N. Mori, Site-specific phosphorylation of SCG10 in neuronal plasticity: role of Ser73 phosphorylation by N-methyl D-aspartic acid receptor activation in rat hippocampus. Neurosci Lett 396, 241-246 (2006).

66. H. Peng, B. E. Derrick, J. L. Martinez, Jr., Identification of upregulated SCG10 mRNA expression associated with late-phase long-term potentiation in the rat hippocampal Schaffer-CA1 pathway in vivo. $J$ Neurosci 23, 6617-6626 (2003).

67. G. P. Shumyatsky et al., stathmin, a gene enriched in the amygdala, controls both learned and innate fear. Cell 123, 697-709 (2005).

68. T. Okazaki et al., SCG10, a neuron-specific growth-associated protein in Alzheimer's disease. Neurobiol Aging 16, 883-894 (1995).

69. J. Wang et al., SCG10 promotes non-amyloidogenic processing of amyloid precursor protein by facilitating its trafficking to the cell surface. Hum Mol Genet 22, 4888-4900 (2013).

70. R. Havekes et al., Gravin orchestrates protein kinase A and beta2-adrenergic receptor signaling critical for synaptic plasticity and memory. J Neurosci 32, 18137-18149 (2012).

71. T. Maki et al., A-Kinase Anchor Protein 12 Is Required for Oligodendrocyte Differentiation in Adult White Matter. Stem Cells 36, 751-760 (2018).

72. C. Shimamoto et al., Functional characterization of FABP3, 5 and 7 gene variants identified in schizophrenia and autism spectrum disorder and mouse behavioral studies. Hum Mol Genet 23, 6495-6511 (2014).

73. S. Yu, L. Levi, G. Casadesus, G. Kunos, N. Noy, Fatty acid-binding protein 5 (FABP5) regulates cognitive function both by decreasing anandamide levels and by activating the nuclear receptor peroxisome proliferator-activated receptor beta/delta (PPARbeta/delta) in the brain. J Biol Chem 289, 12748-12758 (2014). 